\title{
Las revistas de Geografía en el Journal Citation Reports: lucro económico versus acceso abierto
}

\author{
Miguel García Martín* \\ * Departamento de Geografía Humana, Universidad de Sevilla \\ Correo-e: mgmartin@us.es
}

Recibido: 30-12-2014; 2a versión: 24-02-2015; Aceptado: 05-03-2015.

Cómo citar este artículo/Citation: García Martín, M. (2015). Las revistas de Geografía en el Journal Citation Reports: lucro económico versus acceso abierto. Revista Española de Documentación Científica, 38(4): e105. doi: http://dx.doi.org/10.3989/ redc. 2015.4.1248

Resumen: En el ámbito de las revistas científicas con un alto impacto conviven fórmulas editoriales muy variadas, donde tienen cabida desde las grandes multinacionales comerciales a los pequeños organismos universitarios de carácter público. Este artículo revisa las características editoriales y la política tarifaria de las revistas de Geografía indexadas en las últimas ediciones de los Journal Citation Reports, desde el análisis concreto de los costes por artículo, por suscripción y para publicar. Se observa una marcada dualidad entre las editoriales impulsadas por el interés económico - grandes firmas comerciales de origen angloamericano, que son hegemónicas- frente a las que se mueven sin ánimo de lucro, muy diversas en su naturaleza y minoritarias en el área de Geografía. En el fondo subyace el debate sobre la necesidad de difundir conocimientos científicos abiertamente y sin restricciones, tras el que asoma el movimiento Open Access.

Palabras clave: Revistas académicas; Geografía; editorial; índice de impacto; acceso abierto; Journal Citation Reports.

\section{Geography Journals in Journal Citation Reports: economic profits versus open access}

Abstract: Within the field of the scientific publishing sphere and high impact journals, there exist a wide variety of formulas ranging from relevant multinational publishing houses to small scholar public organisms. This paper analyzes the editorial features and pricing policies of geographical journals indexed in Journal Citation Reports, taking into account individual article costs, subscriptions and pay-per-publish fees. It is observed a contrasted duality between commercial publishers -Anglo-American commercial firms, which are hegemonic- and non-profit publishers, which are heterogeneous and represent the minority. Underlying the text is the debate about the necessity of spreading scientific knowledge openly and without restrictions, an issue that has to do with Open Access principles.

Keywords: Scientific journals; geography; publisher; impact factor; Open Access; Journal Citation Reports.

Copyright: () 2015 CSIC. Este es un artículo de acceso abierto distribuido bajo los términos de la licencia Creative Commons Attribution-Non Commercial (by-nc) Spain 3.0. 


\section{INTRODUCCIÓN Y OBJETIVOS}

\subsection{Revistas científicas e impacto editorial}

En el actual contexto académico las revistas científicas suponen uno de los principales medios de difusión y discusión de los conocimientos científicos que genera la comunidad investigadora. La calidad de las investigaciones, ante todo medida por el impacto que su publicación genera en otras investigaciones, no solo determina el mérito profesional de los científicos, sino que condiciona los criterios de la gestión política del aparato científico: evaluación de los currículos personales e institucionales, distribución de recursos, recompensas, etc. (Delgado-López-Cózar, 2010; Ruiz-Pérez y otros, 2010). En España, las distintas agencias públicas de evaluación (nacionales y autonómicas) otorgan un peso muy relevante a las publicaciones en revistas con índice de calidad relativo - revistas indexadas. Dentro de estas, se apunta a las revistas incluidas en los índices agrupados en Journal Citation Reports (JCR) como las revistas "de calidad" (Agencia Nacional de Evaluación de la Calidad y Acreditación, 2007, 2008; Agencia Nacional de Evaluación y Prospectiva, 2007; Boletín Oficial del Estado no 290, 01/12/2014). Si bien también se asumen otros indicadores y bases de datos, llama la atención la posición prevalente de estos índices, que aparecen siempre primeros en los documentos donde se enumeran los criterios de evaluación. En cualquier caso, son la referencia, y así queda expresado, por poner un ejemplo, en la normativa del programa de acreditación para el acceso a los cuerpos universitarios docentes (Agencia Nacional de Evaluación de la Calidad y Acreditación, 2008): "publicaciones en revistas de reconocido prestigio e incluidas en los catálogos tipo [sic] Journal Citation Reports o equivalentes en cada especialidad" (p. 48). La Comisión Nacional Evaluadora de la Actividad Investigadora también es explícita al respecto: "Con carácter orientador, para obtener una evaluación positiva en las áreas relacionadas con la Geografía, se requiere un mínimo de tres artículos en revistas indexadas en JCR Social Sciences Edition o SCOPUS" (Boletín Oficial del Estado no 290, 01/12/2014, p. 98.216). Precisamente esta última resolución, la más reciente en el tiempo, introduce como alternativa para la evaluación de la calidad investigadora un indicador distinto al de Thomson Reuters como es el SCImago Journal and Country Rank (SJR), que se calcula a partir de la base de datos Scopus, propiedad de Elsevier.

El uso de un indicador de impacto de una revista como Journal Citation Reports - generado a partir de la herramienta informática Web of Scien$c e$, en la actualidad explotada por la corporación
Thomson Reuters - ha suscitado variadas críticas. Ante todo, esta base de datos adolece de un triple sesgo: temático, geográfico y lingüístico (DelgadoLópez-Cózar y otros, 2005). Existe un claro predominio de revistas indexadas en $J C R$ en los campos de las ciencias experimentales y de la salud, en detrimento de las áreas aplicadas y tecnológicas, las Ciencias Sociales y las Humanidades. Por otro lado, la inmensa mayoría de las revistas que componen este índice están editadas en Estados Unidos y Reino Unido -en las ediciones Science y Social Science de JCR 2012 estos dos países aportaban cerca del $60 \%$ de todas las revistas indexadas (Thomson Reuters, 2013)-; le siguen en importancia otros países europeos noroccidentales, como Países Bajos o Alemania. Y por último, y en parte como consecuencia de lo anterior, el idioma predominante en estas revistas es el inglés, en perjuicio del resto de lenguas. De hecho, de todos los artículos recogidos por las dos anteriores ediciones de esta base de datos para el periodo 2005-2010, entre un $94 \%$ y un $96 \%$ de los mismos estaban escritos en inglés (Plaza-Gómez y otros, 2013). Una de las ventajas que, como alternativa, ofrece el índice SJR de Scopus frente al índice JCR de Thomson Reuters es su mayor apertura geográfica $y$, en consecuencia, lingüística: de todas las revistas que en 2012 recogía este primer índice, tan solo 50,3 \% proceden de Estados Unidos y Reino Unido (SCImago, 2015). La incorporación de más títulos procedentes de terceros países convierte al SJR en un índice con una mayor presencia proporcional de otros idiomas más allá del inglés (Santa y HerreroSolana, 2010).

Por otro lado, y desde una perspectiva mucho más amplia, el establecimiento de unos indicadores de la calidad científica que se basan en un argumento cuantitativo (el impacto medido por el número de citas) y no cualitativo, genera suspicacias. La consigna "más es mejor" aplicada al ámbito académico ha acabado por convertir el hecho de publicar en un fin en sí mismo, en lugar de ser un medio para hacer partícipe al resto de la comunidad científica y a la sociedad del conocimiento generado (Fischer y otros, 2012; Scheckman, 2013). Asimismo, una parte importante del debate crítico se ha enfocado hacia los aspectos bibliométricos más metodológicos de los índices de impacto, poniendo de manifiesto que son instrumentos válidos aunque imperfectos (incompletos) para la evaluación de la producción científica. Toda esta corriente discordante queda bien reflejada en los principios que inspiran la San Francisco Declaration on Research Assessment (DORA), un manifiesto de pública adscripción fundamentado en la necesidad de mejorar los mecanismos de evaluación de la producción científica. Partiendo de la idea de que el contenido 
científico implícito de una contribución científica (un artículo en una revista) es mucho más importante que los indicadores métricos o la identidad de la propia revista, este manifiesto recomienda "Do not use journal-based metrics, such as Journal Impact Factors (JIFs), as surrogate measures of the quality of individual research articles, to assess an individual scientist's contributions, or in hiring, promotion, or funding decisions" (American Society for Cell Biology, 2012).

Sin embargo, en la literatura científica son menos frecuentes las reacciones que cuestionan la supremacía de las herramientas que desarrolla Thomson Reuters en tanto que productos comerciales. Estos argumentos reprochan que las administraciones públicas, en el ejercicio de unas competencias evaluadoras que exigen trasparencia, publicidad, imparcialidad y ecuanimidad, se dejen orientar por quienes no están en la obligación de asumir dichos principios. Como empresa líder en el sector editorial y de la comunicación, sus intereses son particulares y están basados en el lucro (para un análisis crítico desde diversos ejes argumentales véase Herrán-Gascón y Villena-Higueras, 2012). Todas estas críticas sí han tenido mayor repercusión en medios más informales, como en prensa especializada, blogs, foros académicos, etc.

Pese a todo lo anterior, el número de revistas españolas en las bases de datos internacionales, con JCR a la cabeza, ha aumentado considerablemente en los últimos años. Y este aumento pone de manifiesto el esfuerzo de cualificación e internacionalización de muchas de ellas. Moreno-Pulido y otros (2013) analizan la evolución positiva de las revistas españolas e hispanoamericanas de Ciencias Sociales indexadas en el anterior catálogo de Thomson Reuters entre 2006 y 2010, observando un incremento muy significativo del número de estas revistas (su presencia se multiplica por 9). Así, tal y como afirman estos autores, "la implantación de una política evaluativa sustentada en indicadores internacionales ha contribuido a mejorar la calidad y visibilidad de las revistas españolas" (p. 7). Con todo, este aumento tan acusado se ha suavizado mucho desde entonces. Si en 2006 estaban indexadas 10 revistas españolas e hispanoamericanas y en 2010 esta cifra aumenta hasta 90, (lo que, efectivamente, multiplica su presencia por 9), en 2012 se cuentan 98 revistas, un incremento proporcional bastante más discreto.

\subsection{Revistas científicas y acceso abierto}

Junto a este asunto del impacto de la producción científica, otro eje argumental que orbita en torno a las revistas académicas es el acceso abierto
(Open Access, $O A$ en sus siglas inglesas), como nuevo paradigma de la publicación de los conocimientos científicos para hacerlos accesibles al conjunto de la sociedad. Los principios que inspiran el movimiento Open Access se basan, en suma, en la disponibilidad gratuita de los materiales científicos en Internet y en la posibilidad de los autores de conservar sus derechos de propiedad intelectual sobre la obra -el artículo científico- (Open Society Institute, 2002). Esta corriente pretende dar respuesta al incremento no proporcionado que las principales editoriales comerciales han aplicado en los precios de las suscripciones periódicas a revistas, lo que ha ido sofocando progresivamente el presupuesto de las bibliotecas universitarias y otros organismos públicos de investigación (Alonso-Arévalo y otros, 2008; Melero y Abad-García, 2008). En todo ello, hay que considerar la situación paradójica por la que la producción científica, elaborada en el seno (con la financiación) de las instituciones públicas de investigación, acabe siendo comercializada por editoriales privadas, que venden a universidades y centros de investigación "su propio trabajo" (Alonso-Arévalo y otros, 2008; Magán y Gimeno, 2008). En consecuencia, desde las administraciones públicas, desde las universidades y los centros de investigación, incluso desde investigadores a título particular ${ }^{1}$ se ha extendido el compromiso de fomentar e incentivar el uso de la filosofía Open Access, como parte fundamental de una política científica y educativa basada en el interés público. De hecho, este compromiso llega a materializarse en norma jurídica a partir de la Ley 14/2011, de 1 de junio, de la Ciencia, la Tecnología y la Innovación, (Boletín Oficial del Estado no 131, 02/06/2011), que en su art. 37 fija la necesidad de difundir en acceso abierto las publicaciones financiadas con fondos públicos.

Como reacción, la industria editorial ha tenido que adaptarse a este nuevo panorama. La solución que vienen aportando las principales firmas distribuidoras de revistas académicas ha sido liberar optativamente al lector del coste por leer los artículos, con la finalidad de darle acceso abierto. En su lugar, es el autor el que asume los costes, el que paga por que su trabajo sea publicado. Esta modalidad, conocida como pago por publicación, (en el ámbito angloparlante se denomina de diversas formas: author fees, author side fees, article processing charge, pay-per-publish, fee-based open-access journals...) garantiza la viabilidad económica de la publicación científica por parte de la editorial sin comprometer el libre acceso de los artículos académicos al público en general. Este equilibro se mantiene porque es el autor, o la institución que financia la investigación, quien aporta el dinero. En este nuevo modelo se alternan las editoriales que 
publican todos sus contenidos en acceso abierto (PLoS, BioMed Central, son dos importantes referentes) frente a las denominadas "híbridas", que ofrecen la doble posibilidad de publicar sin costes, lo que implica un acceso restringido mediante la tradicional suscripción, o de pagar por publicar en $O A$-alternativa adoptada por grandes firmas editoriales de larga tradición como Springer, Elsevier, etc.- (Björk, 2012). Otra pieza que matiza y diversifica el panorama del acceso a las publicaciones es la relativa a los repositorios institucionales, donde los autores tienen la alternativa de publicar versiones no definitivas de sus artículos (borradores conocidos como versiones preprint y postprint) bajo el permiso de la editorial, que se reserva el derecho sobre la versión definitiva.

El hecho de pagar por publicar en revistas científicas ha sido, desde su origen, objeto de distintas críticas. Algunos de los argumentos que cuestionan o reflexionan sobre esta modalidad se pueden sintetizar en las siguientes premisas:

- Ante todo, pagar para que una publicación científica -avalada por un proceso de revisión por pares- sea publicada origina un conflicto de integridad editorial (Kapovich, 2011; Truth, 2012). Esto es, si el proceso de publicar genera unos ingresos derivados del importe de publicación (el denominado author fee, article procesisg charge...), las editoriales podrían verse seducidas por los beneficios económicos, comprometiendo la calidad y el rigor científico. Algunos autores distinguen incluso una práctica fraudulenta en determinadas editoriales de dudosa reputación, denominadas "depredadoras", que cobran por publicaciones carentes de un proceso serio de revisión científica y depuración editorial (Beall, 2012).

- Por otro lado, se podría objetar el pago por publicar cuando los principales actores en la obtención de trabajos científicos de calidad, que son autores y revisores, no cobran por su trabajo (al menos, no participan directamente de los beneficios del negocio editorial). Algunos estudios han intentado cuantificar estos costes virtuales (monetarios y no monetarios) no contemplados en el cálculo presupuestario de las revistas científicas. Si bien la edición, publicación y distribución son funciones fundamentales en la generación de los resultados científicos, representan una pequeña parte de los costes en todo el sistema de la comunicación académica, (Research Information Network, 2008; Van Noorden, 2013). Menos aún si cabe en el ámbito de la edición electrónica, donde una parte importante de estos costes se abaratan. Desde este punto de vista, las voces críticas con el hecho de pagar por publicar alegarían un rechazo doble, bajo la máxima: "no solo no cobro por mi trabajo, sino que debo pagar por él".

- El acceso abierto responde a unos ideales igualitarios que pretende hacer accesible los resultados de la investigación a quienes no tienen medios económicos para sufragar las suscripciones. Se alude a menudo a los países pobres (mediando el eufemismo de "países en vías de desarrollo", etc.) como uno de los grandes beneficiarios de esta filosofía. Sin embargo, como también recuerda Kapovich (2011), si importante es el acceso a los artículos (como lectores) para un desarrollo abierto y en igualdad de condiciones a la investigación científica, más importante si cabe es el acceso a su publicación (como autores). Ocurre que se subsidia el conocimiento de los sectores periféricos y más pobres, al condenarlos a ser los actores pasivos de la producción científica, pues pueden recibir los conocimientos en forma de artículos, pero no generarlos, dado que hay que pagar por publicar. Se podría generar así un flujo perverso, unidireccional, de transferencia de conocimientos desde los grandes centros productores (universidades e instituciones de investigación con importantes recursos financieros) hasta el resto de la comunidad científica internacional. Este último asume dicho capital (el conocimiento científico) pero no participa de su construcción. Este desequilibrio se asemeja al que, de forma muy simplificada, ocurre en macroeconomía: los países de la periferia científica exportan materias primas, de poco valor añadido, e importan maquinaria pesada y tecnología, de alto valor añadido, lo que desequilibra en su contra las balanzas comerciales (bananas por medicamentos). Si bien es cierto que muchas editoriales ofrecen precios reducidos para los investigadores de países con escasos recursos (el llamado fee waiver), esto no deja de reforzar la idea de subsidiariedad, de actitud patriarcal o paternalista que subyace tras la doctrina de pagar por publicar.

- El movimiento $O A$, con o sin pago por publicar, ha podido suponer una revolución en la difusión de la investigación científica, al modificar las reglas económicas del juego. Sin embargo, en el contexto académico iberoamericano, en general, y español, en par- 
ticular, el impacto de esta posible revolución ha sido mucho más discreto, por cuanto que estas revistas ya seguían una línea de servicio público que las han hecho tradicionalmente accesibles a toda la comunidad científica. La verdadera revolución estriba en la tecnología de Internet, que ha facilitado la distribución digital y abierta de las revistas en español que hasta entonces se editaban en papel (y bajo suscripción). Hay que tener en cuenta que las revistas iberoamericanas están publicadas en su mayoría por editores institucionales, esto es, grupos de investigación, departamentos universitarios, sociedades científicas, etc., que distribuyen gratuitamente sus versiones electrónicas (Rodríguez-Yunta, 2012; Alonso-Gamboa y Reyna-Espinosa, 2012). Estos editores institucionales se diferencian de los editores comerciales, habituales en el mundo anglosajón, por no tener el ánimo de lucro propio de la empresa. El sostenimiento de un modelo editorial de revistas científicas basado en la vocación de servicio público no es incompatible con un negocio editorial igualmente dedicado a ello. Sin embargo, se deslegitima el derecho a exigir el pago por publicar bajo la máxima de la rentabilidad económica, puesto que muchas revistas -algunas de las cuales mantienen un elevado nivel de calidad académica - salen adelante con los discretos presupuestos de las instituciones que las publican.

- En línea con el anterior argumento, se podría afirmar que las publicaciones de calidad son más costosas, y que pagar por publicar puede redundar en la calidad del artículo. Algunos autores afirman que mientras más riguroso y selectivo es un proceso de revisión editorial, más costoso es cada uno de los artículos finalmente aceptados (Kaiser, 2010; Van Noorden, 2013). Sin entrar a valorar lo acertado de este razonamiento, sí es discutible que se pueda aspirar a una alta calidad en la producción científica de una revista académica sin la necesidad de un aparato financiero como el que sólo las grandes editoriales angloamericanas manejan. Recurriendo a cierto eslogan publicitario, se puede argumentar que la calidad no es cara.

En el trasfondo de toda esta controversia subyace el hecho de evaluar el coste real de las publicaciones científicas, al margen de la conveniencia de uno u otro modelo, es decir, pay-per-publish versus suscripciones tradicionales. Frente al incremento tan acusado del precio de las suscripciones, algunas voces (Solomon y Björk, 2012) opinan que aplicar una tarifa al autor por publicar en acceso abierto puede resultar más económico para las instituciones públicas que, de una u otra forma, son las que sufragan el coste de la difusión de los conocimientos científicos vía revistas. En otros foros se critica que algunas editoriales que de forma híbrida ofrecen parte de sus contenidos en abierto - previo pago por parte del autor- no repercutan estos ingresos en una reducción o rebaja de las suscripciones (Kiley, 2009; ETH-Bibliothek, 2014). El asunto clave está en valorar el precio justo de publicar artículos y editar revistas. En cualquier caso, esto escapa a los objetivos más inmediatos de este artículo, si bien esta contribución puede ayudar a abrir líneas de investigación en esa misma dirección.

\subsection{El caso particular de las revistas científicas de Geografía}

¿Qué papel juegan las revistas de Geografía en este panorama académico y editorial? A priori, estas revistas no tendrían por qué presentar una tendencia muy distinta a las correspondientes a otras disciplinas próximas, al menos en el contexto de las Ciencias Sociales y las Humanidades. El hecho de centrarse aquí en un ámbito concreto de conocimiento responde más bien a intereses metodológicos, puesto que las revistas de Geografía aparecen bien delimitadas dentro de un área propia en los distintos instrumentos de análisis de la calidad de las publicaciones científicas, a pesar de la naturaleza mustidisciplinar y heterodoxa de saber geográfico. Por su parte, ello facilitaría la extrapolación de bastantes conclusiones a otras áreas de conocimiento afines.

Sin embargo, también hay circunstancias que son particulares para la geografía y para su producción académica (precisamente por esa cualidad multidisciplinar antes mencionada). La literatura académica ofrece algunos trabajos enfocados a la situación de la producción académica en Geografía, en general, y de las revistas en particular. De un lado, hay que subrayar la tendencia positiva que han experimentado las revistas españolas de Geografía en los últimos años, cuya presencia en los principales indicadores internacionales de calidad ha ido en aumento, aunque de manera todavía discreta (Gutiérrez-Puebla, 2013). En este caso, las revistas de Geografía experimentan un comportamiento similar al del conjunto de las Ciencias Sociales, al que se ha hecho referencia con anterioridad. Por otro lado, es el área de conocimiento de la Geografía Física el ámbito que mayor aportación genera a los indicadores de calidad de la producción científica, ya sea en forma de citas internacionales de artículos en revistas españolas (García 
Ruiz, 2008) o de otros indicadores, caso del índice h (Lasanta Martínez y García Ruiz, 2013). Esta última circunstancia refuerza el tratamiento particular de estas revistas dentro de las Ciencias Sociales y las Humanidades, precisamente por la crítica de algunos autores - véase los anteriormente citadosal sesgo de la geografía hacia estas ramas sociales y humanas, y a que no esté incluida como parte de las Ciencias Naturales. Un vistazo somero a algunos de los artículos de mayor impacto internacional en Geografía basta para descubrir que temas tales como la geomorfología cuaternaria, las variaciones paleoclimáticas o la rectificación ortofotogramétrica de imágenes aéreas (por poner algunos ejemplos al azar) están considerados como parte de un conocimiento propio de las Ciencias Sociales y las Humanidades. Y esto es algo que resulta difícil de asumir, aun cuando no dejan de ser conocimientos verdaderamente geográficos.

Así, las revistas de Geografía (tanto a nivel internacional como en el ámbito español) han sido objeto de un considerable interés por parte de los investigadores. La mayor parte de estos enfoques se centran en los aspectos bibliométricos, en el peso relativo de las citas como indicadores del impacto, en el sesgo que ejerce el ámbito angloparlante, en la distribución temática y geográfica, etc. Aunque algunos trabajos llegan incluso a tratar las características editoriales de quienes publican las revistas, se observan ciertas lagunas en análisis centrados en los costes de distribución de esta producción científica, esto es, en las condiciones de venta de las revistas y sus artículos o en su libre acceso, cuestiones estrechamente relacionadas con el modelo editorial, ora privado-empresarial, ora público-institucional. Tan sólo cabe mencionar la aportación empírica de Vandermotten (2012), quien pone en relación las revistas de Geografía con su modo de distribución comercial o de libre difusión. En este caso, se llega a detectar que el acceso abierto $(O A)$ "está casi ausente en los países donde la difusión de la producción científica está controlada por las grandes compañías editoriales internacionales: Reino Unido, Países Bajos y, en menor medida, Estados Unidos" (párr. 19, traducido). El contraste se produce con las revistas en lenguas latinas, editadas en Francia, España, Portugal, Brasil, etc. La filosofía open access está mucho más extendida entre las editoriales de revistas de Geografía de estos últimos países.

Este artículo pretende, en parte, solventar la ausencia de los análisis sobre las revistas científicas (en este caso en el ámbito de la Geografía) precisamente desde la óptica de la editorial que publica y distribuye los conocimientos científicos en la forma de artículos. Esta investigación tiene como objetivo el análisis de las editoriales de revistas de Geografía con un alto impacto, a partir de su reparto proporcional y de los costes de distribución de artículos y números (issues). Asimismo, se pretende clasificar las revistas en posibles tipologías partiendo del comportamiento de dichos costes y de la política comercial o de libre acceso. De la discusión de los posteriores resultados se podrían extraer conclusiones sobre la existencia de distintos modelos editoriales donde confluyan en distinta proporción los principios de servicio público y atención a la comunidad científica frente al interés económico particular.

\section{METODOLOGÍA DE ESTUDIO}

Para el análisis de las características editoriales de las revistas de Geografía se ha utilizado como referencia la base de datos Journal Citation Reports (edición Social Sciences) de los años 2011, 2012 y 2013. Esta herramienta organiza las revistas incluidas en categorías temáticas, entre las que hay una propia para la Geografía (Geography). Para este periodo de tres años se han identificado un total de 78 revistas, entendidas como la muestra integral que representa a las revistas de mayor impacto en el mundo académico y científico de la disciplina geográfica ${ }^{2}$. Son, por tanto, el objeto particular de análisis de esta investigación. De las anteriores, hasta 71 revistas aparecen a lo largo de los tres años, y sólo se han contado 7 revistas que aparecen o desaparecen de la base de datos en algún momento determinado.

A continuación se han examinado una por una las características editoriales de las revistas. Para ello se ha consultado la información disponible en los sitios web de sus respectivas editoriales. Se ha recopilado información sobre la naturaleza del propio organismo editorial; su país de procedencia; el idioma de publicación; y los costes de publicación, distribución y suscripción, esto es, el coste de un artículo completo (issue), el coste de la suscripción a un año y el precio que se aplica al autor por publicar (pay per publish, en caso de que se aplique). En la mayoría de los casos dicha información estaba disponible para su consulta en la propia web. En los casos en los que hubo confusión, ambigüedad o falta de información, se contactó directamente con la empresa o institución, obteniendo respuestas satisfactorias en todos casos.

Esta comprobación revista por revista ha permitido detectar diferencias entre la información ofrecida por la herramienta JCR y las propias editoriales, como puede ser el idioma de publicación. Por poner un ejemplo, en algunos casos la aplicación de Thomson Reuters clasifica el idioma de 
ciertas revistas como multilanguage, cuando luego se comprueba que el único idioma aceptado por la editorial es el inglés.

Todo este volumen de información ha sido tabulado y clasificado en una tabla de síntesis, donde se recogen los principales indicadores (apéndice $A$ ). El análisis y la posterior discusión del conjunto de los datos permitirán elaborar una radiografía del panorama editorial de las revistas de Geografía.

\section{ANÁLISIS DE LOS RESULTADOS}

\subsection{Características regionales y lingüísticas}

Antes de entrar en un estricto análisis de la política comercial y editorial de las revistas, conviene inspeccionar someramente sus respectivos ámbitos lingüísticos y regionales (entendido como la distribución geográfica por regiones globales). Las 78 revistas objeto de análisis tienen, tal y como se ha venido observando en la introducción, un claro sesgo anglosajón. La figura 1 muestra esta distribución según el país de origen de la editorial y el idioma (o idiomas) en que publican.
Así, la mayoría de las revistas proceden de editoriales angloamericanas (50 revistas), predominando el origen británico. El resto de revistas se concentra en otros países europeos, destacando Alemania (5 revistas) y Países Bajos (4 revistas). En España, por su parte, se editan dos revistas geográficas. La concentración lingüística en torno al inglés es si cabe mayor, ya que algunas de las revistas editadas en países no angloparlantes ofrecen la posibilidad de publicar en este idioma. Así, más del $80 \%$ de las revistas se publican en inglés. Buen ejemplo de ello se observa en revistas como las eslovenas o checas, cuyas lenguas vernáculas son de difusión más limitada (allí se publica alternativamente también en inglés). En suma, hasta 9 revistas utilizan varios idiomas de publicación. Significativos son los casos de la Revue de géographie alpine (francesa) y de Scripta Nova (española), que ofrecen a sus autores la posibilidad de publicar en bastantes idiomas (incluso gallego o catalán en este último caso), lo que las convierte en las únicas revistas de Geografía genuinamente "multilingüísticas".

Figura 1. País de origen e idioma de publicación de las revistas

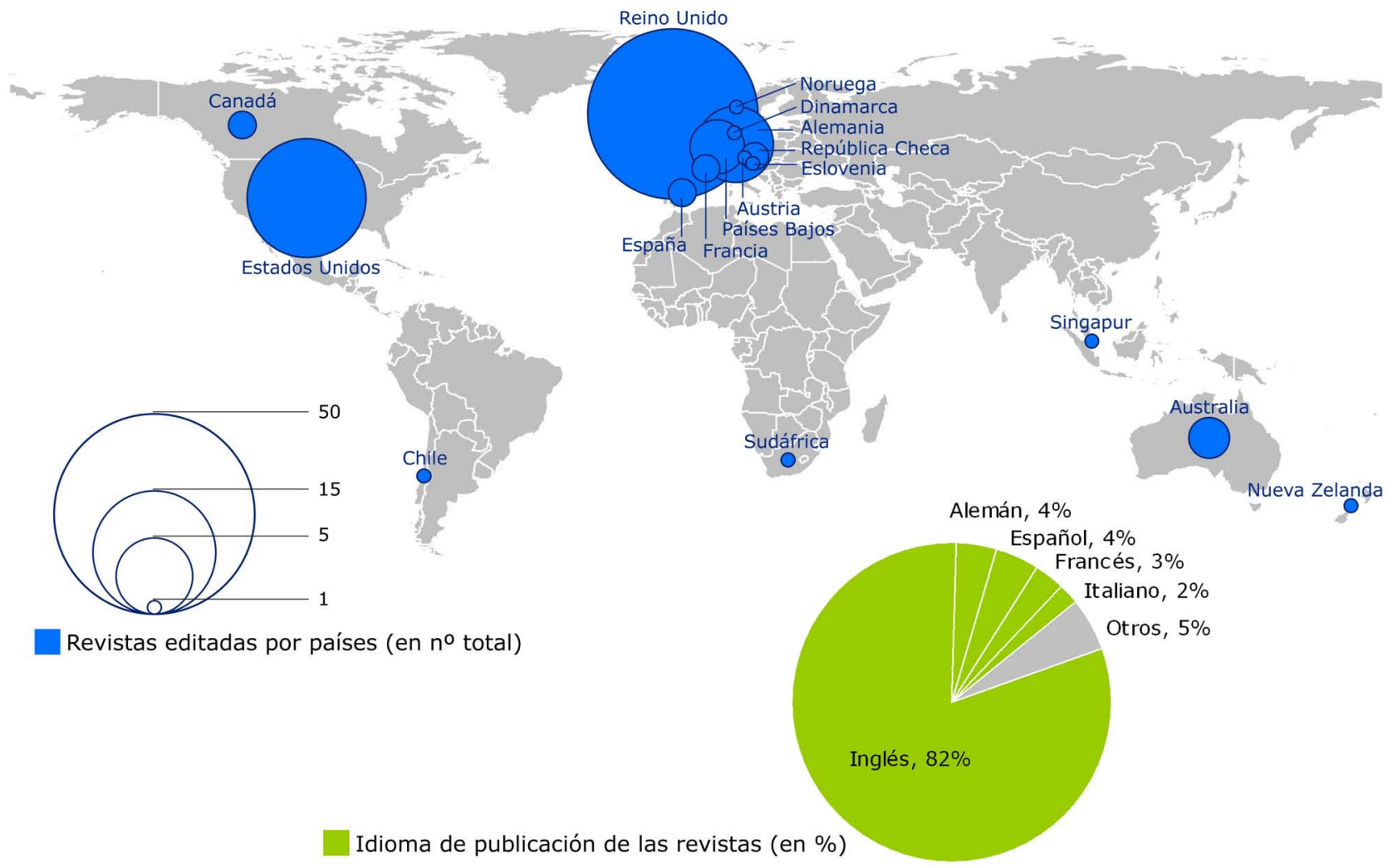




\subsection{Tipo de organismo editorial}

Las revistas también pueden clasificarse atendiendo al organismo editorial. En este caso, las revistas de Geografía que aparecen en los últimos índices $J C R$ han sido publicadas por un total de 23 editoriales, aunque con un reparto muy desigual, como muestra la figura 2. Así, cabe destacar que tan solo tres editoriales concentran dos tercios de todas las revistas publicadas. Esto es, el $13 \%$ de los editores acaparan el $66 \%$ de las revistas, con un peso muy relevante de Taylor \& Francis y Wiley, puesto que ambos conglomerados editoriales representan más de la mitad del conjunto. En el extremo opuesto se encuentra la mayoría de los organismos editoriales, que aportan una única revista al total. A medio camino, firmas como Oxford University Press, Sage Publications, Springer, etc. publican una pequeña cantidad de revistas, entre 2 y 3 .

Si se clasifican los distintos organismos editoriales atendiendo a su función y su naturaleza como entidades públicas o privadas, se observa que la mayor parte $(83 \%)$ de las revistas están publicadas por editoriales comerciales, del sector privado. Frente a estas, una minoría bascula a partes iguales entre las asociaciones académicas, científicas y profesionales, de un lado, y los departamentos e institutos universitarios y de investigación, de otro. Se trata de una minoría tipológica que se mueve, en suma, en la órbita de lo público. Eso sí, en la primera tipología, relativa a editoriales comerciales, se ha incluido a Oxford University Press, que a pesar de ser una editorial universitaria muestra un marcado enfoque comercial.
Tras el análisis de estos datos subyace una primera reflexión evidente: existe una tendencia clara hacia la concentración de la mayor parte de las revistas de Geografía en unas pocas compañías editoriales, muy similares en cuanto a su naturaleza como entidades privadas y del ámbito anglosajón. Frente a este reparto concentrado de "muchas revistas en pocas manos", una minoría de editoriales, diversas en lo regional, lingüístico y tipológico, deben repartirse el resto de títulos publicados.

\subsection{Análisis de los costes}

Por su parte, uno de los objetivos centrales de este artículo es el análisis del los costes de acceso, suscripción y publicación que aplican las revistas de Geografía. Así, partiendo de una disección elemental entre las editoriales con una política de acceso abierto (Open Access) frente a las que aplican algún tipo de pago o tarifa comercial, el propósito aquí es evaluar con detalle las distintas variables económicas y monetarias que caracterizan la edición y distribución de los conocimientos geográficos vía revistas académicas.

Para ello se han consultado en los propios portales web de cada revista los distintos costes aplicables: el coste de un artículo suelto, el coste de la suscripción anual y el coste por publicar un artículo (en el caso de revistas que aplican dichos importes para hacer accesible el artículo). Cabe hacer un par de consideraciones metodológicas al respecto. Por un lado, hay editoriales que detallan el precio de sus productos en diferentes divisas simultánea-

Figura 2. Reparto del número de revistas según la editorial (izquierda) y el tipo de organismo editorial (derecha)
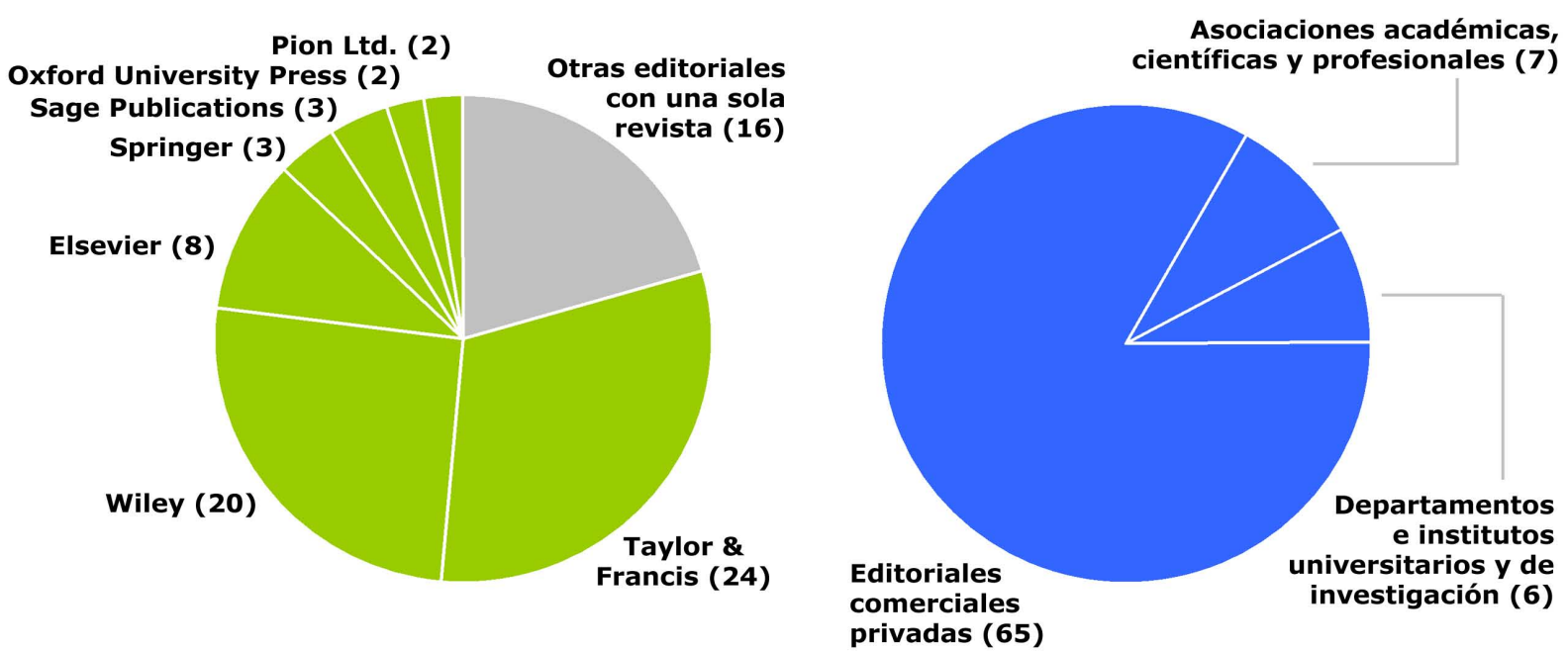
mente, por lo general en euros, dólares y libras esterlinas. En estos casos simplemente se ha tomado como valor el euro (aún cuando las relaciones de cambio entre unas divisas y otras son bastante arbitrarias por parte de la editorial). En otros casos, se detallaba el precio en una divisa distinta al euro, que es la moneda de referencia en esta investigación. En consecuencia, se han convertido estas divisas (casi siempre dólares y libras esterlinas) a euros a partir del tipo de cambio medio de los 12 últimos meses, para equilibrar las fluctuaciones en el valor de unas respecto de otras. Así, entre noviembre de 2013 y octubre de 2014 el tipo de cambio medio del euro $(\epsilon)$, calculado a partir de los valores medios mensuales ha sido de: 1,349 dólares estadounidenses (\$); 0,814 libras esterlinas $(£)$ (Banco de España, 2014). Por otro lado, las editoriales detallan los importes sin impuestos, ya que varían dependiendo del país del usuario/ suscriptor. El precio final de los productos sería, en consecuencia, mayor. De cualquier forma, los valores aquí están calculados sin impuestos, para facilitar el análisis comparativo entre casos.
Así, un total de 74 revistas, la inmensa mayoría, ofrecen la posibilidad de acceder a artículos sueltos, mayoritariamente mediante la propia descarga digital del archivo en formato electrónico. Esto no es posible tan solo en cuatro revistas, para las que es necesario adquirir el volumen completo (el denominado issue). La figura 3 muestra un histograma de frecuencias donde se han clasificado por rangos los distintos precios por artículo.

Para la mayoría de las revistas se ofrecen artículos previo pago, y el coste más común oscila entre los 25 y los 30 euros. Sin embargo, hay un número reducido pero significativo (10 revistas) en las que se ofrecen los artículos de forma gratuita, por medio de su descarga directa. Al margen de estas cifras generales, muchas de las revistas que ofrecen los artículos previo pago publican algunos de ellos bajo la fórmula Open Access. En estos casos se trata del autor (o su institución de investigación) quien elije pagar el denominado autor processing charge para que su acceso sea público. Por ello, este tipo de artículos aparecen a lo largo de los ejemplares de estas revistas sin un orden

Figura 3. Costes de un artículo

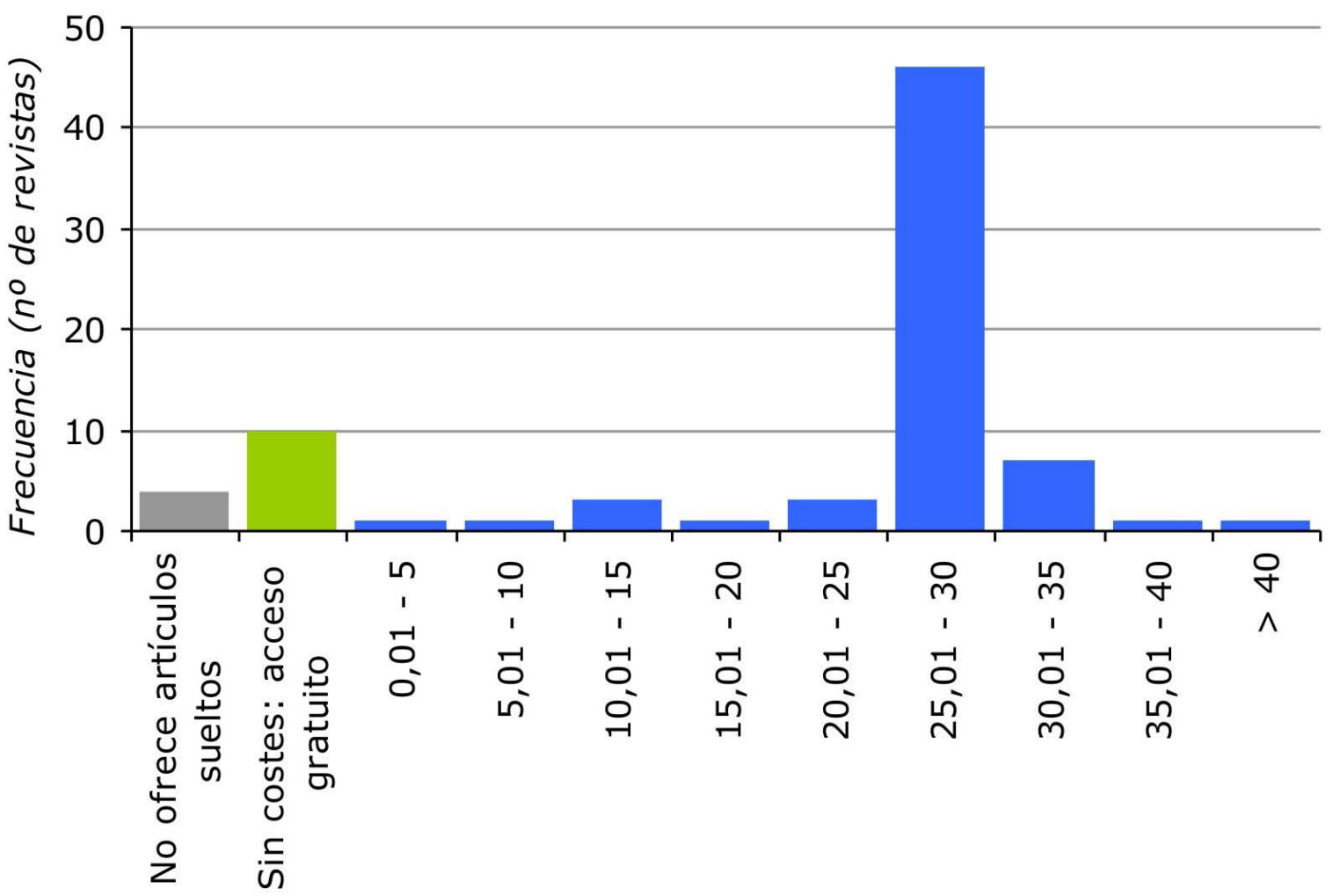


aparente, con una distribución muy desproporcionada entre las que ofrecen bastantes de estos artículos bajo esta fórmula y las que presentan muy pocos casos.

Otra variable económica complementaria a la anterior es la de los costes de suscripción anual, calculados en base al último año (2013). Dado que bastantes editoriales ofrecen distintos precios en función del soporte de la revista - en papel, electrónico o ambos-, la naturaleza jurídica del usuario - suscripciones individuales, universidades e instituciones públicas o empresas privadas - y el ámbito de origen, los cálculos están estandarizados para: una suscripción en doble formato papel y electrónico (o electrónico si no lo ofertan conjuntamente) de una institución universitaria pública española de tamaño medio (entre 10.000 y 25.000 usuarios). El uso de este criterio responde ante todo a cuestiones de orden instrumental, para facilitar análisis comparativos entre editoriales. Hay que recordar que las suscripciones a revistas suelen formalizarse como parte de paquetes de productos más amplios negociados entre las editoriales y las instituciones universitarias. En consecuencia, este análisis debe manejarse con la debida cautela, como forma de establecer pautas comparables entre precios hipotéticos. La figura 4 muestra una distribución de las revistas en función del precio de suscripción anual. Así, tan solo en 7 revistas (menos del $10 \%$ ) se prescinde de tarifa de suscripción dado que el acceso a sus artículos es gratuito y su medio de distribución electrónico. La mayor parte de las revistas (un total de 52; dos tercios) se concentra en un rango de precios inferior a los 1.000 euros, mientras que un número significativo de las mismas supera este precio (18 revistas; $23 \%$ ).

Por su parte, el análisis de los costes de publicación en acceso abierto $(O A)$ revela un comportamiento muy distinto del anterior, como se observa en la figura 5 . Así, se distingue claramente un predominio acusado de revistas (un total de $49 ; 63 \%)$ que aplican una tarifa elevada al autor, entre los 2.000 y los $2.500 €$, si este desea que su artículo sea de libre acceso, es decir, sea gratuito para el público. El resto de revistas ofrece distinto tipo de soluciones. Algunas de ellas plantean esta misma opción, aunque con precios más reducidos (entre los 500 y los $1.500 €$ ). Otras revistas no exigen pago alguno al autor y además distribuyen los artículos bajo la doctrina

Figura 4. Costes de suscripción anual a las revistas

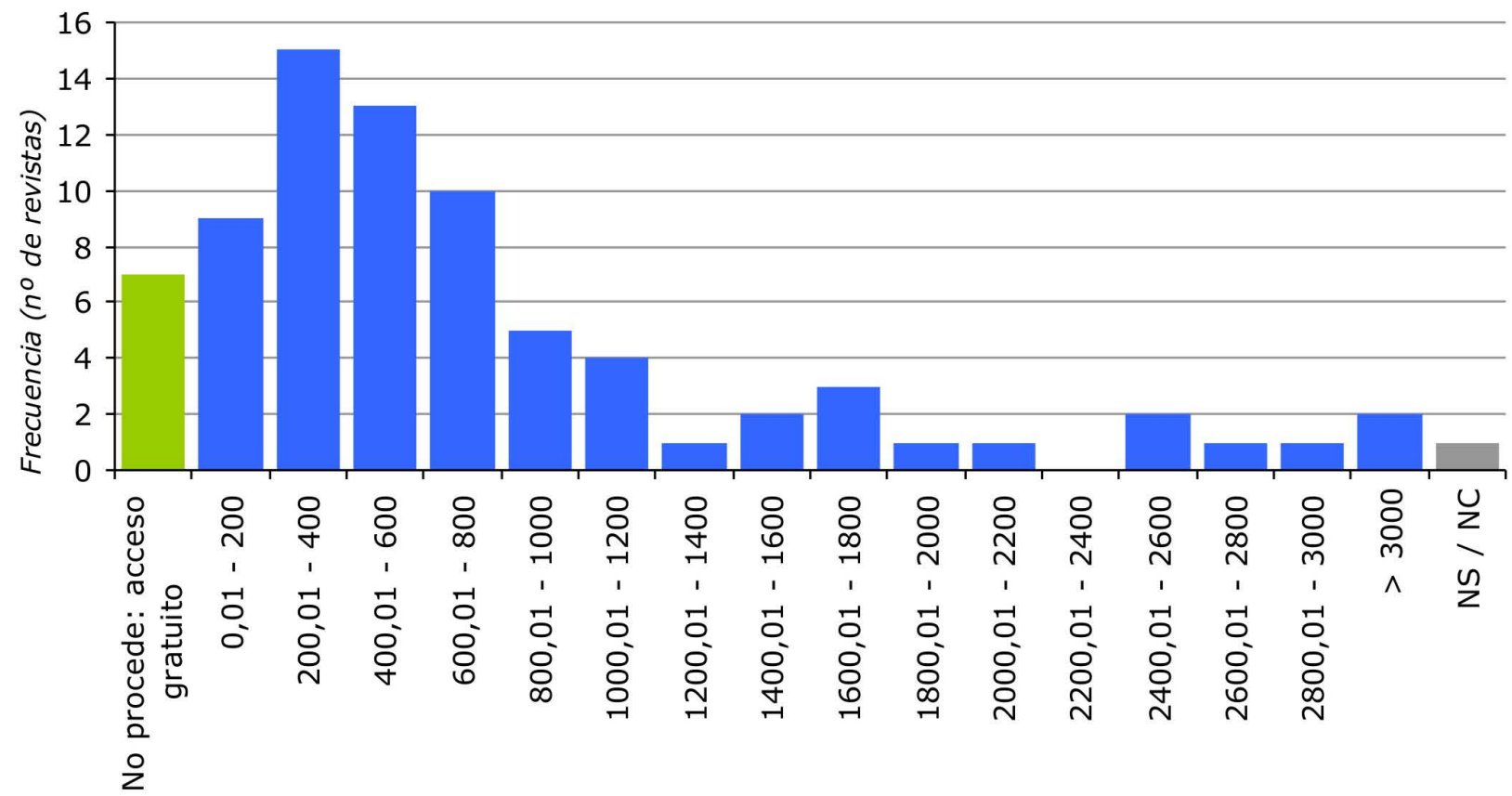


Open Access sistemáticamente. Hay un pequeño número de revistas (un total de 3 ) en las que publicar siempre presenta un coste para el autor, aunque con fórmulas distintas: Island Studies Journal aplica $10 €$ por artículo -en concepto de donación, lo que la acerca más al conjunto de revistas sin costes al autor que de pago-; el Boletín de la Asociación de Geógrafos Españoles aplica $100 €$ por autor, si bien los socios de esta asociación están exentos; y Die Erde, la revista de la Sociedad Geográfica de Berlín, aplica una tasas de $12,5 €$ por página. Por último, hay 8 revistas (algo más del $10 \%$ ) que no ofrecen la posibilidad de publicar en libre acceso.

Simplificando este análisis de costes de publicación en acceso abierto se observan cuatro posibilidades elementales: El autor tiene la posibilidad de pagar para que el lector no lo haga (opción que practica la mayor parte de las revistas, denominadas en consecuencia "híbridas"); el autor paga siempre, no así el lector; el lector paga siempre (generalmente vía suscripción); y, por último, ni autor ni lector pagan. Es esta última opción la que más se aproxima a una concepción genuinamente gratuita de la difusión del conocimiento científico.

De todo estos análisis de costes llama la atención la diversidad de tarifas que se dan en los precios de un artículo individual y en los precios de suscripción anual frente a la política tarifaria fija que establecen editoriales como Francis \& Taylor o Wiley con respecto a los coste de publicación en acceso abierto. En estos dos últimos casos, el precio por publicar es casi siempre invariable independientemente de las revistas o del número de páginas del artículo - por norma general $2.150 €$ y $2.223,87$ $€(3.000 \$)$, respectivamente- mientras que adquirir un artículo o pagar una suscripción oscila ampliamente entre unas y otras revistas dentro de estos mismos grupos editoriales.

Figura 5. Costes por publicar en acceso abierto (OA)

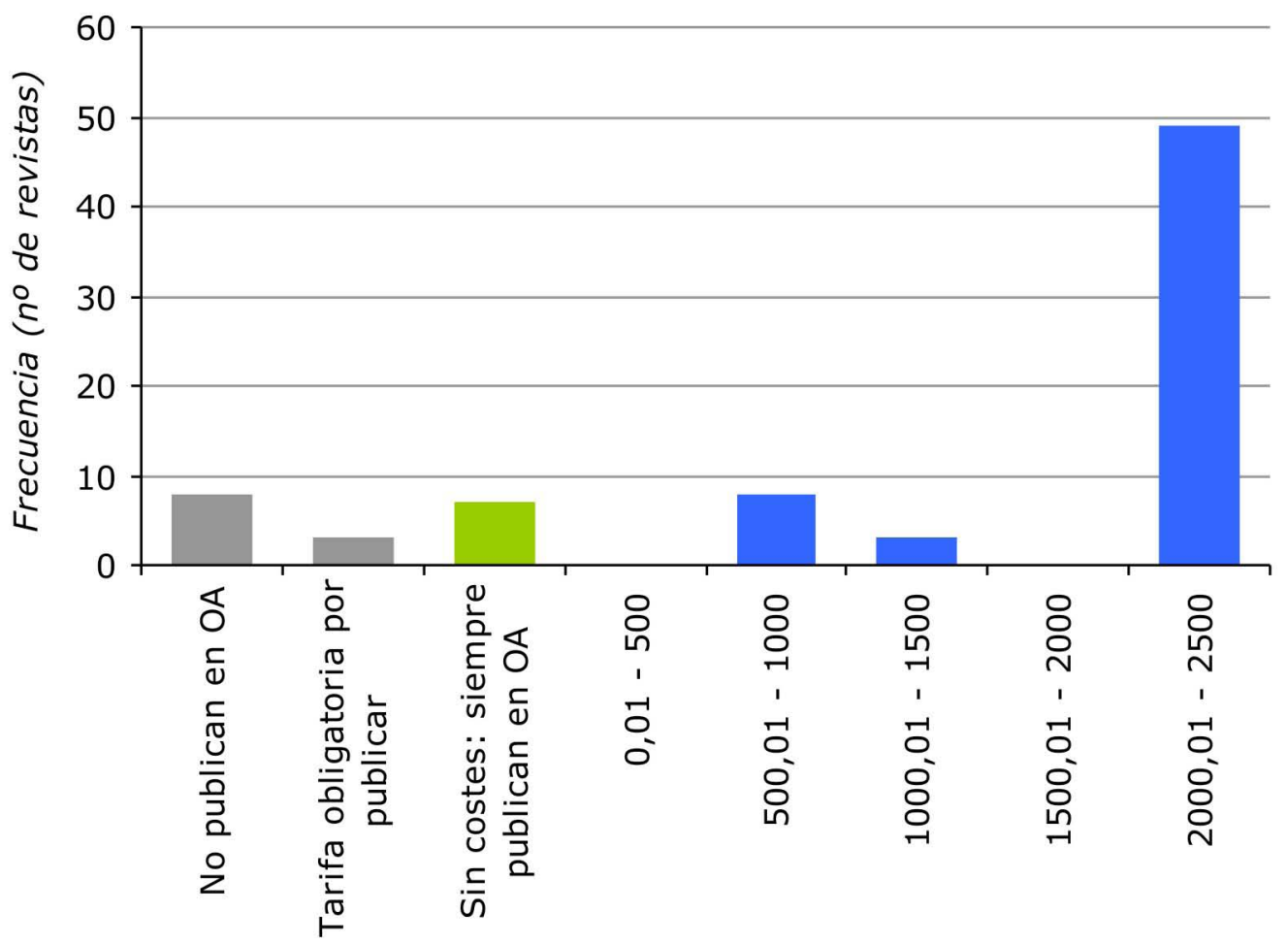




\subsection{Caracterización de las revistas por tipos}

Todas estas características centradas en los costes de acceso, distribución y publicación, junto con las variables lingüísticas, regionales y editoriales permiten establecer determinadas tipologías basadas en la concurrencia de los distintos factores explicados. En consecuencia, a simple vista se pueden detectar dos grandes comportamientos diferenciados:

- Un primer tipo está caracterizado por las revistas de origen angloamericano editadas en inglés por unas pocas grandes corporaciones editoriales privadas, con costes por artículo y de suscripción anual muy variables, frente a un coste por publicación en acceso abierto $(O A)$ elevado y bastante constante (por lo general superior a $2.000 €$ ). Casi todas estas revistas, que se pueden considerar de pago, ofrecen la alternativa al autor de pagar por publicar para eximir al lector de hacerlo. Esta tipología aglutina a la mayoría de las revistas de Geografía objeto de este estudio.

- Un segundo tipo, mucho más heterogéneo, engloba a un minoría de revistas de Geografía que publican en distintos idiomas junto con el inglés, como el alemán, español, francés, etc. en ocasiones con la presencia de varios idiomas en una misma publicación. Esta tipología procede predominantemente de países europeos no angloparlantes (con la excepción de una de las revistas canadienses y otra de Chile) y cada una de ellas está editada por una única editorial, con predominio de la vocación pública: departamentos universitarios o asociaciones científicas. En casi todos los casos se ofrecen en acceso abierto los artículos individuales, si bien las suscripciones oscilan levemente entre aquellas editoriales - pocas- que mantienen el doble formato electrónico y en papel. El coste para autores por publicar también varía, ya que si bien en la mayoría de estas revistas no se aplica ningún tipo de tasas (practican una política $O A$ sin costes para el autor), otras editoriales exigen un pago para la publicación. En cualquier caso, estos costes están muy por debajo de los que aplican las editoriales comerciales que ofrecen esta posibilidad.

En suma, el análisis de los distintos costes asociados al proceso editorial de estas publicaciones científicas revela una dicotomía o, mejor dicho, una dualidad marcada y contrastada entre dos tipos bien distintos de revistas geográficas. El atributo que distingue a unas de otras es el lucro frente a la ausencia de costes para el lector y el autor. La figura 6 sintetiza de manera esquemática las cualidades que caracterizan ambas realidades. La columna de la izquierda muestra las características "estandar" de la primera tipología, asociada a las revistas con vocación comercial. Por su parte, la columna de la derecha muestra las características "estandar" de la segunda tipología, que se vincula con las revistas con vocación de servicio público y acceso abierto. Junto a las cualidades ya tratadas, se observa además que los mayores índices de impacto registrados se concentran en la primera tipología de revistas. Sin entrar en mayores consideraciones, cabe reflexionar sobre el mayor impacto que producen en la comunidad científica revistas con recursos económicos más voluminosos, frente al impacto científico más limitado -entendiendo este desde una perspectiva estrictamente bibliométrica- de las revistas editadas sin ánimo comercial.

\section{DISCUSIÓN Y CONCLUSIONES}

Este conjunto de análisis da pie a ciertas reflexiones, argumentos y conclusiones que se enlazan con los debates que se han puesto de relieve al principio. Por un lado, en el campo de las revistas de Geografía se detecta una realidad caracterizada por la dualidad entre dos tipos distintos de políticas editoriales. Frente al predominio de unas pocas editoriales comerciales que concentran la mayor parte de esta producción científica en torno a un centro gravitatorio que es territorial y lingüísticamente angloamericano, asoman las que bien podrían denominarse "minorías editoriales": un conjunto de revistas que es minoritario en la producción científica total, pero variado, diverso y heterogéneo desde el punto de vista cualitativo, así como enfocado de forma generalizada a la vocación pública. La política que orienta al primer grupo está marcada por el interés particular y el ánimo de lucro, mientras que en el caso de las llamadas minorías existe una tendencia común hacia el acceso abierto generalizado. Esto no significa que todas las revistas de este segundo tipo se inspiren en las iniciativas del Open Access. Algunas de ellas no lo hacen de forma explícita - de hecho, tan sólo 5 de las revistas de Geografía estudiadas aparecen catalogadas en DOAJ, un directorio de revistas de acceso abierto con más de 10.000 revistas indexadas en todo el mundo-. Pero el interés general y la vocación de servicio público orientan su ejercicio editorial, como ponen de manifiesto los escasos costes de acceso a la información, más enfocados a sufragar los estrictos gastos de publicación que a generar negocio con ellos. 
Figura 6. Caracterización tipológica de las revistas

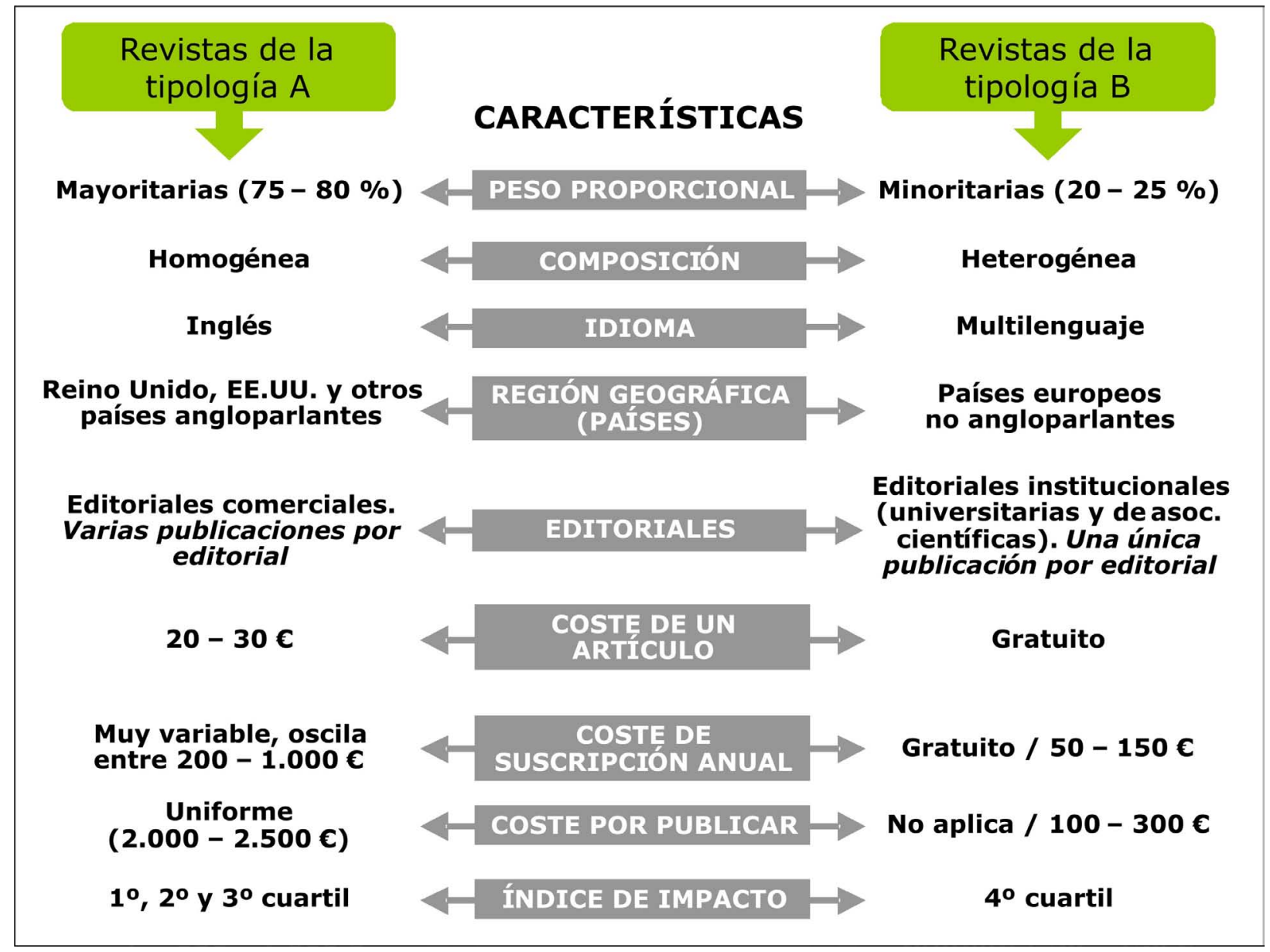

A partir de esta primera conclusión general surgen una serie de reflexiones derivadas. A este respecto se da pie a cuestionar, cuando menos, que el inglés deba ser la lengua que vehicule la transmisión internacional de conocimientos. Bien es cierto que si ésta se ha convertido en la lengua de referencia en la investigación y la ciencia, no lo es así a la hora de liderar el movimiento de acceso abierto al conocimiento científico, al menos en el área de la Geografía. El español, el francés, el alemán... (incluso lenguas de difusión bastante limitada como el checo o el esloveno) están a la misma altura que el inglés en el número de revistas que distribuyen sin ningún tipo de restricciones ni costes de publicación. Y si el inglés sigue siendo una alternativa para la publicación gratuita (para el lector tanto como para el autor) de artículos geográficos de máximo impacto, ello se debe a que muchas de estas revistas compaginan este idioma con las lenguas vernáculas de sus respectivos países de origen. Dicho de otro modo, si un investigador geógrafo quiere publicar en inglés a coste cero tanto para él como para el lector, puede hacerlo en bastantes de estas revistas, que ofrecen dicha alternativa, pero no puede hacerlo en revistas editadas en Reino Unido o EE.UU., pues dicha opción no es posible. El inglés es, en este caso, una lengua favorecida y privilegiada por el mundo editorial de vocación comercial.

Otra de las ideas que subyacen tras una lectura detenida de todo lo dicho está en relación con la definición y el sentido mismo de la filosofía Open Access. Esta iniciativa favorece el acceso libre y gratuito de las publicaciones científicas (es decir, sin restricciones económicas, técnicas o administrativas) a cualquier lector, a la vez que garantiza al autor el control sobre los derechos de propiedad intelectual de su obra. Sin embargo, hay una diferencia significativa entre esta doctrina y aquella que persigue tanto el acceso libre y gratuito de una obra por parte del lector como de su publicación por parte del autor. Esto es, la iniciativa $O A$ ampara ante todo al lector, imponiendo costes al autor si fuera necesario, como así ponen en práctica mu- 
chas editoriales comerciales por medio del author processing charge. Pero como se ha podido comprobar, hay editoriales del ámbito de las instituciones públicas que no solo ofrecen todos los artículos de forma abierta, sino que también consideran que el autor debe estar libre de toda restricción económica, lo que va más allá de los propios principios inspiradores del movimiento Open Access. Por tanto, en estos casos desaparecen los costes para el lector tanto como para el autor, en un ejercicio de verdadera ideología abierta y universal ${ }^{3}$. Esto se hace posible porque las instituciones que liberan al lector y al autor de los costes de publicación encuentran financiación en muchos casos en ayudas y fondos públicos o como parte de los presupuestos ordinarios para investigación. El acceso abierto y universal, que no gratuito, forma parte así de la inversión y el gasto públicos.

No cabe restarle mérito a todos aquellos partícipes esforzados en acogerse a las ideas Open Access, pero es cierto que hay ciertas editoriales que ya venían practicando una filosofía similar antes incluso de que esta iniciativa se institucionalizara a principios de la década de 2000. A este respecto, el $O A$ adquiere todo su sentido cuando se plantea como alternativa a un sistema tradicional que considera evidente el que alguien (autor o lector) deba acarrear con los costes de publicación, como ocurre en países con una larga trayectoria editorial de base comercial (como Reino Unido o EE.UU., por poden los dos, pero no los únicos, ejemplos más evidentes). Sin embargo, en el ámbito hispanoamericano, así como en otras regiones de semejante comportamiento, caso de Francia, la filosofía Open Access no supone un cambio radical de las reglas editoriales, puesto que una parte importante de la producción de los conocimientos geográficos ya venía recayendo sobre editoriales sin ánimo

\section{NOTAS}

[1] Un buen ejemplo de esta actitud particular se puede observar en el blog de Tim Gowers (https://gowers.wordpress.com/2012/01/21/ elsevier-my-part-in-its-downfall/), de cuyo eco se llega a hacer el diario británico The Guardian (http://www.theguardian.com/technology/2012/apr/22/academic-publishing-monopoly-challenged)

[2] Con todo, existen revistas que publican trabajos de Geografía sin estar clasificadas dentro de esta categoría temática, como es el caso de las revistas dedicadas a Estudios urbanos (Urban studies), Demografía (Demography) o Estudios de lucro que distribuían sus revistas sin costes ni para el autor ni para el lector.

Todas estas ideas convergen en una reflexión concluyente aparentemente evidente, a la que no siempre se le presta atención. Publicar en revistas con altos índices de impacto supone un criterio bastante aceptado de calidad y de reconocimiento científico e institucional para un autor. Sin embargo, como se ha puesto de manifiesto a lo largo de esta investigación, existen revistas en el área de conocimiento de la Geografía -y probablemente suceda algo similar en otras áreas de las Ciencias Sociales- que forman parte de esa élite científica reconocida en el JCR y que desarrollan su actividad editorial sin necesidad de exigir un precio ni al lector ni al autor. $Y$ ese es un indicador de calidad, o cuando menos de compromiso con el servicio público, que debería ser también tenido en cuenta, en tanto que se compite en un plano de desigualdad contra editoriales comerciales que sí recurren a este tipo de financiación. Y desde luego, debería ser tenido en cuenta ya que se generan conocimientos científicos sin comprometer unos costes que, de una manera u otra, supondrían un gasto público.

En suma, se puede publicar en revistas con altos índices de impacto inspiradas en el acceso abierto, pues ello no compromete la calidad de la contribución. Se puede publicar en un idioma distinto al inglés, pues también otras lenguas participan de la transferencia de conocimientos de calidad por medio de revistas científicas. Y se debe reconocer el mérito de ciertas editoriales que, publicando sin renunciar a su idioma vernáculo y sin obtener beneficios sustantivos por ello, compiten con las grandes revistas comerciales anglosajonas por aparecer entre los más altos índices de calidad científica y editorial. 


\section{REFERENCIAS}

Agencia Nacional de Evaluación de la Calidad y Acreditación (2007). Programa de evaluación de profesorado para la contratación. Principios y orientaciones para la aplicación de los criterios de evaluación. Disponible en Internet [última consulta: 02/06/2014]: http://www.aneca.es/content/download/11202/122982/file/pep_criterios_070515.pdf

Agencia Nacional de Evaluación de la Calidad y Acreditación (2008). Programa ACADEMIA. Principios y orientaciones para la aplicación de los criterios de evaluación. Disponible en Internet [última consulta: 02/06/2014]: http://www.aneca.es/content/ download/10527/118089/version/1/file/academia_14_ppiosyorientaciones.pdf

Agencia Nacional de Evaluación y Prospectiva (2007). Criterios de evaluación de la $I+D$ en Ciencias Sociales. Disponible en Internet [última consulta: 02/06/2014]: http://www.idi.mineco.gob.es/stfls/ MICINN/Investigacion/FICHEROS/2007-criteriosevaluacion-ccss3.pdf

Alonso Arévalo, J.; Subirats Coll, I.; Martínez Conde, M. L. (2008). Informe APEI sobre el acceso abierto. Gijón: Asociación Profesional de Especialistas en Información.

Alonso Gamboa, J. O.; Reyna Espinosa, F. R. (2012): La revista académica iberoamericana en Latindex. Una visión de 15 años. Biblioteca Universitaria, vol. 15 (2), 123-138.

American Society for Cell Biology (2012). San Francisco Declaration on Research Assessment. Disponible en Internet [última consulta: 22/12/2014]: http://www. ascb.org/dora-old/files/SFDeclarationFINAL.pdf

Banco de España (2014). Boletín Estadístico, noviembre 2014. Disponible en Internet [última consulta: 16/12/2014]: http://www.bde.es/f/webbde/ SES/Secciones/Publicaciones/InformesBoletinesRevistas/BoletinEstadistico/14/Fich/be_noviembre2014_es.pdf

Beall, J. (2012): Predatory publishers are corrupting open access. Nature News, vol. 489, 179. http:// dx.doi.org/10.1038/489179a

Björk, B.C. (2012): The hybrid model for open access publication of scholarly articles: A failed experiment? Journal of the American Society for Information Science and Technology, vol. 63 (8), 1496-1504.

Boletín Oficial del Estado (2011). Ley 14/2011, de 1 de junio, de la Ciencia, la Tecnología y la Innovación. 02/06/2011, no 131, sec. I. 54387-54455.

Boletín Oficial del Estado (2014). Resolución de 26 de noviembre de 2014, de la Comisión Nacional Evaluadora de la Actividad Investigadora, por la que se publican los criterios específicos aprobados para cada uno de los campos de evaluación. 01/12/2014, no 290, sec. III, 98204-98219.
Delgado López-Cózar, E. (2010). Claroscuros de la evaluación científica en España. Boletin Medes: Medicina en Español, vol. 4, 25-29.

Delgado López-Cózar, E.; Jiménez Contreras, E.; Ruiz Pérez, R.; López Herrera, A. G.; Gacto Colorado, M. J.; Torres Salinas, D.; Moneda Corrochano, M.; Ruiz Baños, R.; Pérez Ortega, J. M.; Bailón Moreno, R.; Poyatos Huertas, E. ; Rodríguez Gálvez, M. J. (2005). IN-RECS: Índice de impacto de las revistas españolas de ciencias sociales. Biblio 3W, Revista Bibliográfica de Geografía y Ciencias Sociales, vol. 10 (574). Disponible en Internet [última consulta: 22/12/2014]: http://www.ub.edu/geocrit/b3w-574.htm

ETH-Bibliothek (2014). Publishing in open-access journals. Disponible en Internet [última consulta: 22/12/2014]: https://www.library.ethz.ch/en/ms/ Open-Access-at-ETH-Zurich/Publishing-in-openaccess-journals

Fischer, J.; Ritchie, E. G.; Hanspach, J. (2012). Academia's obsession with quantity. Trends in Ecology and Evolution, vol. 27 (9), 473-474. http:// dx.doi.org/10.1016/j.tree.2012.05.010

García Ruiz, J. M. (2008). Las citas internacionales de las revistas españolas de Geografía. Boletín de la Asociación de Geógrafos Españoles, vol. 46, 207-225.

Gutierrez Puebla, J. (2013). Los medios de difusión de la investigación. En: Lasanta Martínez, T.; Martín Vide, J. (coordinadores) La Investigación Geográfica en España (1990-2012). Madrid: Asociación de Geógrafos Españoles, Instituto Pirenaico de Ecología (CSIC), Centro de Ciencias Humanas y Sociales (CSIC), 205-220.

Herrán Gascón, A; Villena Higueras, J. L. (2012). La "cultura del impacto JCR": el caso del área de Didáctica y Organización Escolar. En: Herrán Gascón, A.; Paredes Labra, J. (Coords.). Promover el cambio pedagógico en la universidad. Madrid: Pirámide, 287-304.

Kaiser, J. (2010): Free Journals Grow Amid Ongoing Debate. Science, vol. 329, 896-898. http://dx.doi. org/10.1126/science.329.5994.896

Kapovich, I. (2011). The dangers of the "author pays" model in mathematical publishing, Notices of the American Mathematical Society, vol. 58 (9), 12941295.

Kiley, R. (2009). Wellcome Trust calls for greater transparency from journals on open access publishing costs. Blog de Europe PubMed Central, 19/10/2009. Disponible en Internet [última consulta: 22/12/2014]: http://blog.europepmc. org/2009/10/wellcome-trust-calls-for-greater.html

Lasanta Martínez, T.; García Ruiz, J. M. (2013). La producción de la geografía española a través de las bases de datos de Scopus e ISI Web of Knowledge. En: Lasanta Martínez, T.; Martín Vide, J. (coordinadores) 
La Investigación Geográfica en España (1990-2012). Madrid: Asociación de Geógrafos Españoles, Instituto Pirenaico de Ecología (CSIC), Centro de Ciencias Humanas y Sociales (CSIC), 221-234.

Magán, J. A.; Gimeno, J. (2008). ¿Es "biblioteconómicamente correcto" el compromiso social de la biblioteca universitaria? Educación y biblioteca, 166 (julio-agosto), 95-101.

Melero, R; Abad García, M. F. (2008). Revistas open access: características, modelos económicos y tendencias. BiD: textos universitaris de biblioteconomia i documentació, 20. Disponible en Internet [última consulta: 22/12/2014]: http://bid. ub.edu/20meler2.htm

Moreno-Pulido, A.; López-González, M. A.; RubioGaray, F.; Ángel Saúl, L.; Sánchez-Elvira-Paniagua, A. (2013). Evolución de las revistas españolas de Ciencias Sociales en el Journal Citation Reports (2006-2010) y su valoración como indicio de calidad en la normativa evaluadora española. Revista Española de Documentación Científica, 36 (3), e014. http://dx.doi.org/10.3989/redc.2013.3.987

Open Society Institute (2002). Budapest Open Access Initiative. Disponible en Internet [última consulta: 22/12/2014]: http://www.budapestopenaccessinitiative.org/

Plaza Gómez, L.M.; Granadino Goenechea, B.; García Carpintero, E. (2013). Estudio bibliométrico sobre el papel del español en ciencia y tecnología. En: García Delgado, J.L.; Alonso Rodríguez, J.A.; Jiménez Jiménez, J.C. (Coords.). El español, lengua de comunicación científica. Madrid; Ariel, Fundación Telefónica, 315-366.

Research Information Network (2008). Activities, costs and funding flows in the scholarly communications system in the UK. Disponible en Internet [última consulta: 22/12/2014]: http://www.rin.ac.uk/system/ files/attachments/Activites-costs-flows-report.pdf

Rodríguez-Yunta, L. (2012): ¿Sustitución de suscripciones a revistas por acceso pay per view? Anuario ThinkEPI, vol. 6, 197-199.

Ruiz Pérez, R.; Delgado López-Cózar, E.; Jiménez Contreras, E. (2010). Principios y criterios utiliza- dos en España por la Comisión Nacional Evaluadora de la Actividad Investigadora (CNEAI) para la valoración de las publicaciones científicas: 1989-2009. Psicothema, vol. 22 (4), 898-908.

Santa, S.; Herrero-Solana, V. (2010). Cobertura de la ciencia de América Latina y el Caribe en Scopus vs Web of Science. Investigación Bibliotecológica, vol. 24 (52), 13-27.

Scheckman, R. (2013). Por qué revistas como 'Nature', 'Science' y 'Cell' hacen daño a la ciencia. El País, jueves 12 de diciembre de 2013.

SCImago (2015). SCImago Journal Rank (SJR) indicator. Disponible en Internet [Última consulta: 23/02/2015]: http://www.scimagojr.com

Shieber, S. M. (2009). What percentage of openaccess journals charge publication fees? The occasional pamphlet, 29/05/2009. Disponible en Internet [última consulta: 23/12/2014]: http:// blogs.law. harvard.edu/pamphlet/2009/05/29/ what-percentage-of-open-access-journals-chargepublication-fees

Solomon, D. J.; Björk, B. C. (2012). A Study of Open Access Journals Using Article Processing Charges. Journal of the American Society for Information Science and Technology, vol. 63 (8), 1485-1495. http://dx.doi.org/10.1002/asi.22673

Thomson Reuters (2013). 2012 Journal Citation Reports $®$. Disponible en Internet [acceso restringido bajo licencia. Ultimo acceso: 02/06/2014]: http:// admin-apps.webofknowledge.com/JCR/JCR

Truth, F. (2012). Pay Big to Publish Fast: Academic Journal Rackets. Journal for Critical Education Policy Studies, vol.10 (2), 54-105.

Van Noorden, R. (2013). The true cost of science publishing. Nature, vol. 495, 426-429. http://dx.doi. org/10.1038/495426a

Vandermotten, C. (2012) Cotation des revues de géographie, impérialisme scientifique anglosaxon et culture de l'excellence marchandisée. Belgeo vol. 1-2, 1-16. Disponible en Internet [Última consulta: 27/08/2014]: http://belgeo.revues.org/7131 


\section{APÉNDICE A}

Características detalladas de las revistas de Geografía en el JCR (edición Social Science) de 2011, 2012 y 2013

\begin{tabular}{|c|c|c|c|c|c|c|c|c|c|c|}
\hline 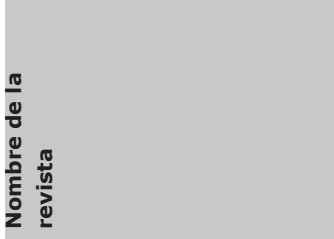 & ž & 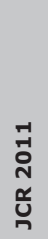 & 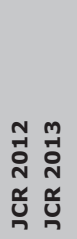 & 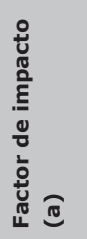 & 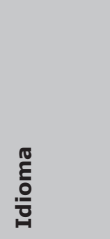 & $\frac{n}{80}$ & 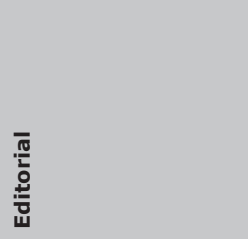 & 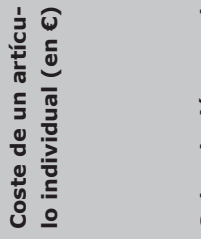 & 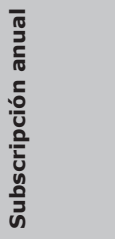 & 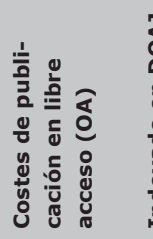 \\
\hline Annals of Regional Science & $\begin{array}{l}0570- \\
1864\end{array}$ & Sí & Sí Sí & 0,739 & Inglés & EE.UU. & Springer & 34,95 & 1059 & 2200 \\
\hline $\begin{array}{l}\text { Annals of the Association of } \\
\text { American Geographers }\end{array}$ & $\begin{array}{l}0004- \\
5608\end{array}$ & Sí & Sí Sí & 2,088 & Inglés & EE.UU. & Taylor \& Francis & 29 & $2552(b)$ & 2150 \\
\hline Antipode & $\begin{array}{l}0066- \\
4812\end{array}$ & Sí & Sí Sí & 1,885 & Inglés & Reino Unido & Wiley & $25,95(c)$ & 988 & 2223,87 \\
\hline Applied Geography & $\begin{array}{l}0143- \\
6228\end{array}$ & Sí & Sí Sí & 2,650 & Inglés & Reino Unido & Elsevier & 26,65 & 1160 & 1334,32 \\
\hline $\begin{array}{l}\text { Applied Spatial Analysis and } \\
\text { Policy }\end{array}$ & $\begin{array}{l}1874- \\
463 x\end{array}$ & No & No Sí & 0,679 & Inglés & Países Bajos & Springer & 39,95 & 370 & 2200 \\
\hline Area & $\begin{array}{l}0004- \\
0894\end{array}$ & Sí & Sí Sí & 1,466 & Inglés & Reino Unido & Wiley & $25,95(c)$ & 347 & 2223,87 \\
\hline Asia Pacific Viewpoint & $\begin{array}{l}1360- \\
7456\end{array}$ & Sí & Sí Sí & 0,525 & Inglés & Australia & Wiley & $25,95(c)$ & 305 & 2223,87 \\
\hline Australian Geographer & $\begin{array}{l}0004- \\
9182\end{array}$ & Sí & Sí Sí & 1,120 & Inglés & Australia & Taylor \& Francis & 29 & 587 & 2150 \\
\hline $\begin{array}{l}\text { Boletin de la Asociacion de } \\
\text { Geografos Espanoles }\end{array}$ & $\begin{array}{l}0212- \\
9426\end{array}$ & Sí & Sí Sí & 0,100 & $\begin{array}{l}\text { Español, } \\
\text { inglés }\end{array}$ & España & $\begin{array}{l}\text { Asociación de Geógra- } \\
\text { fos Españoles }\end{array}$ & -0 & NS/NC & $\begin{array}{l}100 / \text { autor } \\
\text { (d) }\end{array}$ \\
\hline $\begin{array}{l}\text { Cambridge Journal of Regions } \\
\text { Economy and Society }\end{array}$ & $\begin{array}{l}1752- \\
1378\end{array}$ & Sí & Sí Sí & 0,696 & Inglés & Reino Unido & $\begin{array}{l}\text { Oxford University } \\
\text { Press }\end{array}$ & 28,17 (c) & 339 & 2400 \\
\hline Cartographic Journal & $\begin{array}{l}0008- \\
7041\end{array}$ & Sí & Sí Sí & 0,230 & Inglés & Reino Unido & Maney Publishing & $121,62(\mathrm{c})$ & 515,97 & 614,25 \\
\hline $\begin{array}{l}\text { Cartography and Geographic } \\
\text { Information Science }\end{array}$ & $\begin{array}{l}1523- \\
0406\end{array}$ & Sí & Sí Sí & 0,500 & Inglés & EE.UU. & Taylor \& Francis & 34 & 184 & 2150 \\
\hline Childrens Geographies & $\begin{array}{l}1473- \\
3285\end{array}$ & Sí & Sí Sí & 1,263 & Inglés & Reino Unido & Taylor \& Francis & 29 & 611 & 2150 \\
\hline $\begin{array}{l}\text { Computers Environment and } \\
\text { Urban Systems }\end{array}$ & $\begin{array}{l}0198- \\
9715\end{array}$ & Sí & Sí Sí & 1,520 & Inglés & Reino Unido & Elsevier & 31,1 & 2049 & 1334,32 \\
\hline Cultural Geographies & $\begin{array}{l}1474- \\
4740\end{array}$ & Sí & Sí Sí & 1,244 & Inglés & Reino Unido & Sage Publications & 22,24 (c) & 638,82 & 982,8 \\
\hline Economic Geography & $\begin{array}{l}0013- \\
0095\end{array}$ & Sí & Sí Sí & 3,281 & Inglés & EE.UU. & Wiley & $25,95(c)$ & 253 & 2223,87 \\
\hline Environment and Planning A & $\begin{array}{l}0308- \\
518 X\end{array}$ & Sí & Sí Sí & 1,694 & Inglés & Reino Unido & Pion Ltd. & $\begin{array}{l}\text { No ofrece artícu- } \\
\text { los sueltos (sólo } \\
\text { por subscripción) }\end{array}$ & 1412,78 & $\begin{array}{l}\text { No publica } \\
\text { en libre } \\
\text { acceso }\end{array}$ \\
\hline $\begin{array}{l}\text { Environment and Planning D - } \\
\text { Society \& Space }\end{array}$ & $\begin{array}{l}0263- \\
7758\end{array}$ & Sí & Sí Sí & 1,729 & Inglés & Reino Unido & Pion Ltd. & $\begin{array}{l}\text { No ofrece artícu- } \\
\text { los sueltos (sólo } \\
\text { por subscripción) }\end{array}$ & 509,83 & $\begin{array}{l}\text { No publica } \\
\text { en libre } \\
\text { acceso }\end{array}$ \\
\hline Erde & $\begin{array}{l}0013- \\
9998\end{array}$ & Sí & Sí Sí & 0,314 & Inglés & Alemania & $\begin{array}{l}\text { Gesellschaft für Erd- } \\
\text { kunde zu Berlin }\end{array}$ & $0(e)$ & 0 & $\begin{array}{l}12,5 / \text { pági- } \\
\text { na (f) }\end{array}$ \\
\hline Erdkunde & $\begin{array}{l}0014- \\
0015\end{array}$ & Sí & Sí Sí & 1,119 & Inglés & Alemania & $\begin{array}{l}\text { Department of Ge- } \\
\text { ography, University } \\
\text { of Bonn }\end{array}$ & 0 & 100 & 0 \\
\hline $\begin{array}{l}\text { Eurasian Geography and Eco- } \\
\text { nomics }\end{array}$ & $\begin{array}{l}1538- \\
7216\end{array}$ & Sí & Sí Sí & 0,827 & Inglés & EE.UU. & Taylor \& Francis & 29 & 677 & 2150 \\
\hline European Planning Studies & $\begin{array}{l}0965- \\
4313\end{array}$ & Sí & Sí Sí & 1,025 & Inglés & Reino Unido & Taylor \& Francis & 29 & 3020 & 2150 \\
\hline
\end{tabular}




\begin{tabular}{|c|c|c|c|c|c|c|c|c|c|c|}
\hline 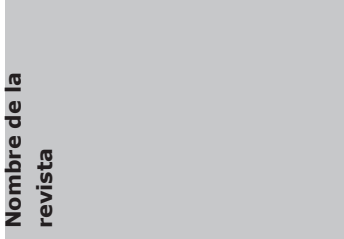 & ž & 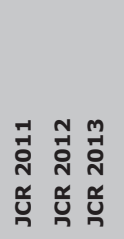 & 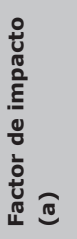 & 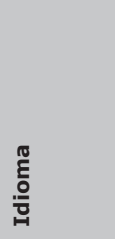 & $\frac{n}{\pi}$ & 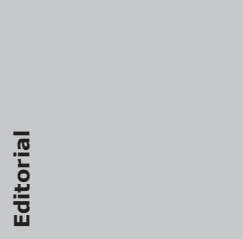 & 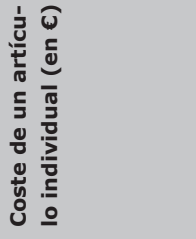 & 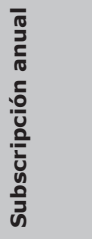 & 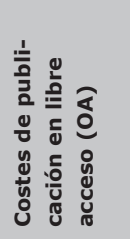 & 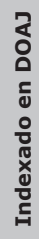 \\
\hline Gender Place and Culture & $\begin{array}{l}0966- \\
369 x\end{array}$ & Sí Sí Sí & 1,105 & Inglés & Reino Unido & Taylor \& Francis & 29 & 1525 & 2150 & \\
\hline Geodetski Vestnik & $\begin{array}{l}0351- \\
0271\end{array}$ & Sí Sí Sí & 0,288 & $\begin{array}{l}\text { Esloveno, } \\
\text { inglés }\end{array}$ & Eslovenia & $\begin{array}{l}\text { Zveza geodetov } \\
\text { Slovenije }\end{array}$ & 0 & 0 & 0 & Sí \\
\hline Geoforum & $\begin{array}{l}0016- \\
7185\end{array}$ & Sí Sí Sí & 1,877 & Inglés & Reino Unido & Elsevier & 14,79 & 1614 & 1334,32 & \\
\hline Geografie & $\begin{array}{l}1212- \\
0014\end{array}$ & Sí Sí Sí & 0,400 & $\begin{array}{l}\text { Checo, } \\
\text { inglés }\end{array}$ & $\begin{array}{l}\text { República } \\
\text { Checa }\end{array}$ & $\begin{array}{l}\text { Česká geografická } \\
\text { společnost }\end{array}$ & 0 & 0 & $0(\mathrm{~g})$ & \\
\hline $\begin{array}{l}\text { Geografisk Tidsskrift / Danish } \\
\text { Journal of Geography }\end{array}$ & $\begin{array}{l}0016- \\
7223\end{array}$ & Sí Sí Sí & 0,727 & Inglés & Dinamarca & Taylor \& Francis & $29(h)$ & 176 & 2150 & \\
\hline $\begin{array}{l}\text { Geografiska Annaler Series B - } \\
\text { Human Geography }\end{array}$ & $\begin{array}{l}0435- \\
3684\end{array}$ & Sí Sí Sí & 0,659 & Inglés & Reino Unido & Wiley & $25,95(c)$ & 527 & 2223,87 & \\
\hline Geographical Analysis & $\begin{array}{l}0016- \\
7363\end{array}$ & Sí Sí Sí & 1,250 & Inglés & EE.UU. & Wiley & $25,95(c)$ & 325 & $\begin{array}{l}\text { No publica } \\
\text { en libre } \\
\text { acceso }\end{array}$ & \\
\hline Geographical Journal & $\begin{array}{l}0016- \\
7398\end{array}$ & Sí Sí Sí & 1,552 & Inglés & Reino Unido & Wiley & $25,95(c)$ & 315 & 2223,87 & \\
\hline Geographical Research & $\begin{array}{l}1745- \\
5863\end{array}$ & Sí Sí Sí & 1,206 & Inglés & Australia & Wiley & 25,95 (c) & 477 & 2223,87 & \\
\hline Geographical Review & $\begin{array}{l}0016- \\
7428\end{array}$ & Sí Sí Sí & 0,588 & Inglés & EE.UU. & Wiley & $25,95(c)$ & 264 & 2223,87 & \\
\hline Geographische Zeitschrift & $\begin{array}{l}0016- \\
7479\end{array}$ & Sí No No & 0,000 & $\begin{array}{l}\text { Alemán, } \\
\text { inglés }\end{array}$ & Alemania & Franz Steiner Verlag & $\begin{array}{l}\text { No ofrece artícu- } \\
\text { los sueltos (sólo } \\
\text { por subscripción) } \\
\text { (i) }\end{array}$ & 175,2 & $\begin{array}{l}\text { No publica } \\
\text { en libre } \\
\text { acceso }\end{array}$ & \\
\hline Geography & $\begin{array}{l}0016- \\
7487\end{array}$ & Sí Sí Sí & 1,094 & Inglés & Reino Unido & $\begin{array}{l}\text { Geographical Asso- } \\
\text { ciation }\end{array}$ & $14,32(j)$ & 125,31 & $\begin{array}{l}\text { No publica } \\
\text { en libre } \\
\text { acceso }\end{array}$ & \\
\hline Geopolitics & $\begin{array}{l}1465- \\
0045\end{array}$ & Sí Sí Sí & 0,778 & Inglés & EE.UU. & Taylor \& Francis & 29 & 558 & 2150 & \\
\hline $\begin{array}{l}\text { Global Environmental Change - } \\
\text { Human and Policy Dimensions }\end{array}$ & $\begin{array}{l}0959- \\
3780\end{array}$ & Sí Sí Sí & 6,000 & Inglés & Reino Unido & Elsevier & 26,65 & 1348 & 2446,26 & \\
\hline Global Networks & $\begin{array}{l}1470- \\
2266\end{array}$ & Sí Sí Sí & 1,255 & Inglés & Reino Unido & Wiley & $25,95(c)$ & 618 & 2223,87 & \\
\hline $\begin{array}{l}\text { Imago Mundi - The Interna- } \\
\text { tional Journal for the History of } \\
\text { Cartography }\end{array}$ & $\begin{array}{l}0308- \\
5694\end{array}$ & Sí Sí Sí & 0,091 & Inglés & Reino Unido & Taylor \& Francis & 29 & 270 & 2150 & \\
\hline $\begin{array}{l}\text { International Journal of Geogra- } \\
\text { phical Information Science }\end{array}$ & $\begin{array}{l}-1365- \\
8816\end{array}$ & Sí Sí Sí & 1,479 & Inglés & Reino Unido & Taylor \& Francis & 34 & 3279 & 2150 & \\
\hline $\begin{array}{l}\text { International Journal of Urban } \\
\text { and Regional Research }\end{array}$ & $\begin{array}{l}0309- \\
1317\end{array}$ & Sí Sí Sí & 1,625 & Inglés & Reino Unido & Wiley & 7,41 (c) & 769 & 2223,87 & \\
\hline Island Studies Journal & $\begin{array}{l}1715- \\
2593\end{array}$ & No Sí Sí & 0,750 & Inglés & Canadá & $\begin{array}{l}\text { Institute of Island } \\
\text { Studies, University of } \\
\text { Prince Edward Island }\end{array}$ & 0 & 60 & $10(k)$ & Sí \\
\hline $\begin{array}{l}\text { Journal of Alpine Research / } \\
\text { Revue de Géographie Alpine }\end{array}$ & $\begin{array}{l}0035- \\
1121\end{array}$ & No No Sí & 0,231 & $\begin{array}{l}\text { Francés, } \\
\text { italiano, } \\
\text { alemán, } \\
\text { español e } \\
\text { inglés }\end{array}$ & Francia & $\begin{array}{l}\text { Association pour la } \\
\text { Diffusion de la Re- } \\
\text { cherche Alpine }\end{array}$ & 0 & 0 & 0 & Sí \\
\hline Journal of Economic Geography & $\begin{array}{l}1468- \\
2702\end{array}$ & Sí Sí Sí & 2,821 & Inglés & Reino Unido & $\begin{array}{l}\text { Oxford University } \\
\text { Press }\end{array}$ & 28,17 (c) & 873 & 2275 & \\
\hline
\end{tabular}




\begin{tabular}{|c|c|c|c|c|c|c|c|c|c|c|c|}
\hline 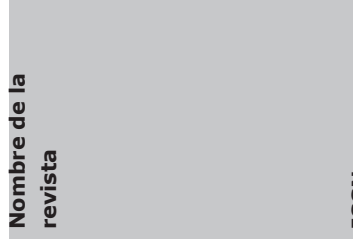 & 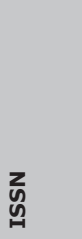 & 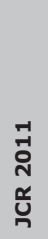 & 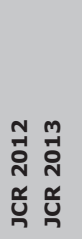 & 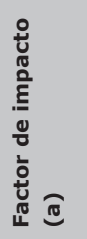 & 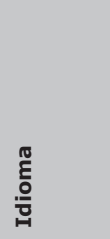 & $\frac{n}{0}$ & 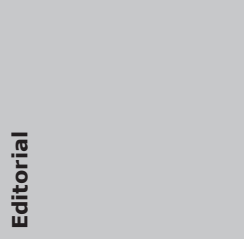 & 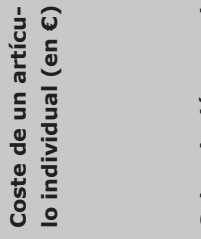 & 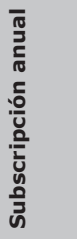 & 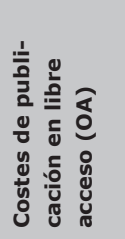 & 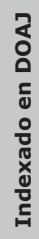 \\
\hline Journal of Geographical Systems & $\begin{array}{l}1435- \\
5930\end{array}$ & Sí & Sí Sí & 1,341 & Inglés & Alemania & Springer & 34,95 & 465 & 2200 & \\
\hline Journal of Geography & $\begin{array}{l}0022- \\
1341\end{array}$ & Sí & Sí Sí & 0,822 & Inglés & EE.UU. & Taylor \& Francis & 29 & 252 & 2150 & \\
\hline $\begin{array}{l}\text { Journal of Geography in Higher } \\
\text { Education }\end{array}$ & $\begin{array}{l}0309- \\
8265\end{array}$ & Sí & Sí Sí & 0,859 & Inglés & Reino Unido & Taylor \& Francis & 29 & 1837 & 2150 & \\
\hline Journal of Historical Geography & $\begin{array}{l}0305- \\
7488\end{array}$ & Sí & Sí Sí & 0,643 & Inglés & EE.UU. & Elsevier & 29,61 & 870 & 555,97 & \\
\hline Journal of Maps & $\begin{array}{l}1744- \\
5647\end{array}$ & Sí & Sí Sí & 0,895 & Inglés & Reino Unido & Taylor \& Francis & $\begin{array}{l}\text { No ofrece artícu- } \\
\text { los sueltos (sólo } \\
\text { por subscripción) } \\
\text { (m) }\end{array}$ & 574 & $2150(n)$ & \\
\hline Journal of Transport Geography & $\begin{array}{l}0966- \\
6923\end{array}$ & Sí & Sí Sí & 2,214 & Inglés & Reino Unido & Elsevier & 29,61 & 924 & 815,42 & \\
\hline Landscape and Urban Planning & $\begin{array}{l}0169- \\
2046\end{array}$ & Sí & Sí Sí & 2,606 & Inglés & Países Bajos & Elsevier & 31,08 & 2975 & 815,42 & \\
\hline Landscape Research & $\begin{array}{l}0142- \\
6397\end{array}$ & Sí & Sí Sí & 0,943 & Inglés & Reino Unido & Taylor \& Francis & 29 & 1009 & 2150 & \\
\hline $\begin{array}{l}\text { Mitteilungen der Osterreichi- } \\
\text { schen Geographischen Gesell- } \\
\text { schaft }\end{array}$ & $\begin{array}{l}0029- \\
9138\end{array}$ & Sí & Sí Sí & 0,250 & $\begin{array}{l}\text { Alemán, } \\
\text { inglés }\end{array}$ & Austria & $\begin{array}{l}\text { Österreichische } \\
\text { Geographische Ge- } \\
\text { sellschaft }\end{array}$ & 20 & 52 & $\begin{array}{l}\text { No publica } \\
\text { en libre } \\
\text { acceso }\end{array}$ & \\
\hline Mobilities & $\begin{array}{l}1745- \\
0101\end{array}$ & Sí & Sí Sí & 1,169 & Inglés & Reino Unido & Taylor \& Francis & 29 & 535 & 2150 & \\
\hline Moravian Geographical Reports & $\begin{array}{l}1210- \\
8812\end{array}$ & No & No Sí & 0,341 & Inglés & $\begin{array}{l}\text { República } \\
\text { Checa }\end{array}$ & $\begin{array}{l}\text { Institute of Geonics, } \\
\text { Academy of Sciences } \\
\text { of the Czech Republic }\end{array}$ & 0 & 0 & 0 & \\
\hline New Zealand Geographer & $\begin{array}{l}0028- \\
8144\end{array}$ & Sí & Sí Sí & 0,526 & Inglés & Nueva Zelanda & aWiley & $25,95(\mathrm{c})$ & 291 & 2223,87 & \\
\hline $\begin{array}{l}\text { Norsk Geografisk Tidsskrift / } \\
\text { Norwegian Journal of Geography }\end{array}$ & $\begin{array}{l}0029- \\
y 1951\end{array}$ & Sí & Sí Sí & 0,698 & Inglés & Noruega & Taylor \& Francis & 29 & 282 & 2150 & \\
\hline Papers in Regional Science & $\begin{array}{l}1056- \\
8190\end{array}$ & Sí & Sí Sí & 1,183 & Inglés & Reino Unido & Wiley & $25,95(c)$ & 772 & 2223,87 & \\
\hline Political Geography & $\begin{array}{l}0962- \\
6298\end{array}$ & Sí & Sí Sí & 2,022 & Inglés & Reino Unido & Elsevier & 31,08 & 1697 & 815,42 & \\
\hline Population Space and Place & $\begin{array}{l}1544- \\
8444\end{array}$ & Sí & Sí Sí & 1,717 & Inglés & Reino Unido & Wiley & $25,95(c)$ & 917 & 2223,87 & \\
\hline Progress in Human Geography & $\begin{array}{l}0309- \\
1325\end{array}$ & Sí & Sí Sí & 4,394 & Inglés & Reino Unido & Sage Publications & $22,24(\mathrm{c})$ & 797,3 & 982,8 & \\
\hline Regional Studies & $\begin{array}{l}0034- \\
3404\end{array}$ & Sí & Sí Sí & 1,756 & Inglés & Reino Unido & Taylor \& Francis & 29 & 2605 & 2150 & \\
\hline $\begin{array}{l}\text { Revista de Geografía Norte } \\
\text { Grande }\end{array}$ & $\begin{array}{l}0718- \\
3402\end{array}$ & Sí & Sí Sí & 0,232 & $\begin{array}{l}\text { Español } \\
(\tilde{n})\end{array}$ & Chile & $\begin{array}{l}\text { Instituto de Geografía, } \\
\text { Pontificia Universidad } \\
\text { Católica de Chile }\end{array}$ & 0 & 0 & 0 & Sí \\
\hline Scottish Geographical Journal & $\begin{array}{l}1470- \\
2541\end{array}$ & Sí & Sí Sí & 0,686 & Inglés & Reino Unido & Taylor \& Francis & 29 & 348 & 2150 & \\
\hline $\begin{array}{l}\text { Scripta Nova - Revista Electró- } \\
\text { nica de Geografía y Ciencias } \\
\text { Sociales }\end{array}$ & $\begin{array}{l}1138- \\
9788\end{array}$ & Sí & Sí Sí & 0,124 & $\begin{array}{l}\text { Español, } \\
\text { portu- } \\
\text { gués, } \\
\text { catalán, } \\
\text { gallego, } \\
\text { italiano }\end{array}$ & España & $\begin{array}{l}\text { Departamento de } \\
\text { Geografía Humana, } \\
\text { Universidad de Bar- } \\
\text { celona }\end{array}$ & 0 & 0 & 0 & Sí \\
\hline
\end{tabular}




\begin{tabular}{|c|c|c|c|c|c|c|c|c|c|c|c|}
\hline 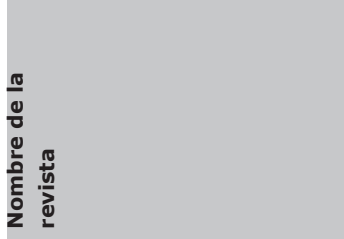 & ž & 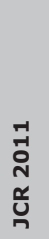 & 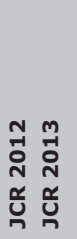 & 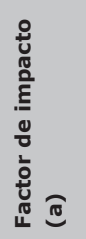 & 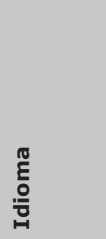 & $\frac{n}{80}$ & $\begin{array}{l}\overline{\frac{\pi}{2}} \\
\frac{0}{2} \\
\frac{\pi}{8}\end{array}$ & 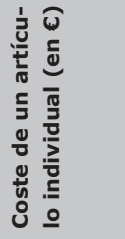 & 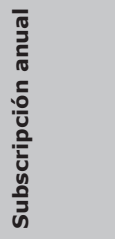 & 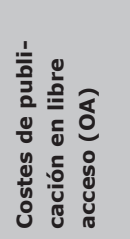 & 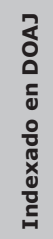 \\
\hline $\begin{array}{l}\text { Singapore Journal of Tropical } \\
\text { Geography }\end{array}$ & $\begin{array}{l}0129- \\
7619\end{array}$ & Sí & Sí Sí & 0,560 & Inglés & Singapur & Wiley & $25,95(c)$ & 346 & 2223,87 & \\
\hline Social \& Cultural Geography & $\begin{array}{l}1464- \\
9365\end{array}$ & Sí & Sí Sí & 1,830 & Inglés & EE.UU. & Taylor \& Francis & 29 & 1155 & 2150 & \\
\hline Sociologia Ruralis & $\begin{array}{l}0038- \\
0199\end{array}$ & No & No Sí & 1,362 & Inglés & Países Bajos & Wiley & $25,95(c)$ & 556 & 2223,87 & \\
\hline $\begin{array}{l}\text { South African Geographical } \\
\text { Journal }\end{array}$ & $\begin{array}{l}0373- \\
6245\end{array}$ & Sí & Sí Sí & 0,481 & Inglés & Sudáfrica & Taylor \& Francis & 29 & 291 & 2150 & \\
\hline Space and Culture & $\begin{array}{l}1206- \\
3312\end{array}$ & Sí & Sí Sí & 0,340 & Inglés & EE.UU. & Sage Publications & $22,24(c)$ & 743,24 & 982,8 & \\
\hline Sud-Ouest Europeen & $\begin{array}{l}1276- \\
4930\end{array}$ & Sí & No No & 0,000 & Francés & Francia & $\begin{array}{l}\text { Presses Universitaires } \\
\text { du Mirail - Toulouse }\end{array}$ & $14,48(p)$ & 73 & $\begin{array}{l}\text { No publica } \\
\text { en libre } \\
\text { acceso }\end{array}$ & \\
\hline $\begin{array}{l}\text { The Canadian Geographer / Le } \\
\text { Géographe Canadien }\end{array}$ & $\begin{array}{l}0008- \\
3658\end{array}$ & Sí & Sí Sí & 1,172 & $\begin{array}{l}\text { Inglés, } \\
\text { francés }\end{array}$ & Canadá & Wiley & $25,95(c)$ & 491 & 2223,87 & \\
\hline The Professional Geographer & $\begin{array}{l}0033- \\
0124\end{array}$ & Sí & Sí Sí & 1,413 & Inglés & EE.UU. & Taylor \& Francis & 29 & $2552(b)$ & 2150 & \\
\hline $\begin{array}{l}\text { Tijdschrift voor Economische en } \\
\text { Sociale Geografie }\end{array}$ & $\begin{array}{l}0040- \\
747 x\end{array}$ & Sí & Sí Sí & 1,012 & Inglés & Países Bajos & Wiley & $25,95(c)$ & 479 & 2223,87 & \\
\hline Transactions in GIS & $\begin{array}{l}1361- \\
1682\end{array}$ & Sí & Sí Sí & 1,000 & Inglés & Reino Unido & Wiley & $25,95(c)$ & 1702 & 2223,87 & \\
\hline $\begin{array}{l}\text { Transactions of the Institute of } \\
\text { British Geographers }\end{array}$ & $\begin{array}{l}0020- \\
2754\end{array}$ & Sí & Sí Sí & 4,011 & Inglés & Reino Unido & Wiley & $25,95(c)$ & 656 & 2223,87 & \\
\hline Urban Geography & $\begin{array}{l}0272- \\
3638\end{array}$ & Sí & Sí Sí & 1,746 & Inglés & EE.UU. & Taylor \& Francis & 29 & 685 & 2150 & \\
\hline Urban Policy and Research & $\begin{array}{l}0811- \\
1146\end{array}$ & Sí & Sí Sí & 0,478 & Inglés & Reino Unido & Taylor \& Francis & 29 & 415 & 2150 & \\
\hline $\begin{array}{l}\text { Zeitschrift fur Wirtschaftsgeo- } \\
\text { graphie }\end{array}$ & $\begin{array}{l}0044- \\
3751\end{array}$ & Sí & Sí Sí & 0,414 & $\begin{array}{l}\text { Alemán, } \\
\text { inglés }\end{array}$ & Alemania & Buchenverlag & 4,99 & 102 & $\begin{array}{l}\text { No publica } \\
\text { en libre } \\
\text { acceso }\end{array}$ & \\
\hline
\end{tabular}

\section{Notas de la tabla del apéndice A:}

(a). Factor de impacto de la última edición JCR donde aparece. Salvo una minoría, es el correspondiente a 2013.

(b). La subscripción es conjunta para Annals of the Association of American Geographers y The Professional Geographer.

(c). El acceso es por 24 horas.

(d). Esta tarifa por autor se aplica siempre (sin costes para los miembros de la Asociación de Geógrafos Españoles).

(e). Acceso gratuito desde 2011.

(f). Esta tarifa por página se aplica siempre.

(g). Esta revista aplica un complemento de 182,08 € (5.000 CZK) si se desea que la institución que financia la investigación objeto del artículo aparezca reflejada.

(h). Los artículos publicados hasta 2001 son gratuítos desde la web de la sociedad geográfica danesa (Det Kongelige Danske Geografiske Selskab). Sin embargo, Taylor \& Francis ofrece estos y los posteriores previo pago.

(i). Se pueden descargar sus artículos vía JSTOR $(23,72 € ; 32 \$)$ o Ingenta Connect $(24,62 € ; 33 \$)$.

(j). El acceso a los artículos es gratuito para los miembros de Geographical Association.

(k). Esta tarifa por artículo se aplica siempre (en concepto de donación).

(m). Hasta 2011, cuando estaba editada por Journal of Maps, los artículos eran gratuitos, previo registro en su web.

(n). Hasta 2011, cuando estaba editada por Journal of Maps, el coste de publicación en libre acceso era de $61,43 €$ (50 £).

(ñ). Eventualmente puede aceptar trabajos en portugués, francés o inglés.

(p). Algunos ejemplares (los de 2012) son de libre acceso. 